\title{
Turismo dark: la muerte como nuevo negocio turístico en España
}

\section{Dark Tourism: Death as a new tourism business in Spain}

\author{
Víctor Calderón Fajardo ${ }^{1^{*}}$
}

\begin{abstract}
Resumen
Se estudia el fenómeno del turismo dark desde sus orígenes, analizando su evolución, embrionaria comercialización y su propio concepto de turismo experiencial como modalidad novedosa en la industria turística. Los objetivos han sido caracterizar el producto y el perfil del consumidor del turismo dark, así como conocer la posible estigmatización del turista dark y la factibilidad de la explotación de dicha modalidad turística en España. Para ello se ha empleado una metodología mixta, cualitativa por un lado, en forma de entrevistas a un colectivo profesional configurado por un elenco variado de escritores, investigadores y profesionales y, por otro, cuantitativa en forma de encuesta y encuesta-experimento a una muestra heterogénea y representativa de turistas y viajeros. Los resultados obtenidos han sido muy significativos: el 66,3\% de los encuestados opinan que se producirá un incremento notable de la industria turística dark en España, aunque señalan diferentes tipos de bloqueos en su desarrollo y comercialización, tanto legales como culturales o éticos. La literatura existente comenzó a forjarse a finales de los noventa, pero con una falsa idea de una heterogeneidad en las actividades turísticas que integran el turismo oscuro en sentido amplio. En esta investigación se establecen, en este sentido, diversas intensidades, categorías y subcategorías de esta modalidad turística complementando y ponderando las ya clásicas de Seaton, Fennon, Foley y Stone. La conclusión principal que se deriva la investigación es que el turismo dark puede ser un catalizador de cambios innovadores en la oferta turística, capaz de valorizar recursos endógenos infrautilizados para el desarrollo y maduración de muchos destinos turísticos en tiempos convulsos y de crisis en la industria turística española.
\end{abstract}

Palabras clave: Tanatoturismo, turismo dark, perfil dark, espectro dark, categorías dark, recursos dark

\begin{abstract}
This research has analysed the phenomenon of dark tourism from its very beginning, its evolution, its embryonic commercialization and even the concept of experiential tourism as a revolution in the tourism industry. The objectives were to reel off the product and the profile of the dark tourism consumer, to know the possible stigmatization of the dark tourist and the feasibility of the exploitation of such typology in Spain. To do so, a double methodology was used: firstly, a qualitative one in the form of interviews with a professional group made up of a varied cast of writers, researchers and professionals and, secondly, a quantitative one in the form of a survey and survey-experiment to a heterogeneous and representative sample of tourists and travellers. The results obtained were highly significant, $66.3 \%$ of people surveyed imagine the possible proliferation of a dark tourism industry in Spain, although they point out different types of blockages such as legal, cultural or ethical for their commercialization. The existing literature began to take shape in the late 1990s, but it involved a false idea of heterogeneity in activity. Therefore, this research creates a single spectrum of intensity and new categories and subcategories by unifying and complementing Seaton, Fennon, Foley and Stone's classic ones. The main conclusion drawn from such research is that dark tourism can be a catalyst for changes, since it is capable
\end{abstract}

${ }^{1}$ Departamento de Economía y Empresa. Universidad Oberta de Cataluña, España. E-mail: vcalderonfa@uoc.edu 
of using dormant endogenous resources for development and territorial transformation in volatile, critical or turbulent times in the Spanish tourism industry.

Keywords: Thanatotourism, dark tourism, dark profile, dark spectrum, dark categories, dark resources

\section{Introducción}

Aunque el turismo dark sea considerado ya un producto turístico innovador, atractivo y complementario a otras tipologías turísticas, parece que no acaba de enraizarse con fuerza en la cultura turística española. Por este motivo, esta investigación se centra en analizar que, a pesar de existir recursos dark en nuestro país, existe una estigmatización del consumidor dark relacionada, quizás, con la ausencia de un tratamiento histórico-cultural adecuado de los recursos que sirven de soporte a esta modalidad turística.

Por otro lado, se muestra claramente la rentabilidad y el éxito de este nicho de mercado en el extranjero y se justifica que para España puede ser una estrategia de producto con potencialidades. Es decir, que el desarrollo del turismo dark en nuestro país podría ser el detonante capaz de rejuvenecer destinos maduros, de fomentar el atractivo de destinos turísticamente en crisis (a través del uso de sus recursos endógenos) o incluso de la oportunidad de diversificar el modelo productivo del turismo en España más allá de los turismos predominantes, masivos y clásicos como son el turismo de sol y playa o el cultural.

En un segundo nivel, se aportan orientaciones para fomentar un nuevo horizonte en la forma de practicar turismo en España, ya que el turismo dark puede ser el catalizador de cambios innovadores capaz de valorizar recursos endógenos infrautilizados en tiempos tan volátiles, críticos o convulsos como los actuales en la industria turística española, así como un posible atractivo diferencial para la dinamización turística en muchos territorios.

Y, finalmente, se ha planteado como objetivo establecer una nueva clasificación, unos nuevos criterios y un espectro dark más completo de las actividades y productos turísticos que lo integran, además de desarrollar un amplio catálogo capaz de asentar unas bases más sólidas para saber identificar y rentabilizar este nicho de mercado turístico.

\subsection{Originalidad y contribución al conocimiento del fenómeno}

Se enmarca en España, aunque con comparaciones a nivel internacional por la popularización y la comercialización del fenómeno dark. Esta investigación está basada en las tendencias turísticas actuales, pero para contextualizar la materia de estudio también se retrotrae a una o dos décadas atrás, cuando comenzaron a gestarse los intereses por estos lugares de turismo oscuro en el Mundo. Las clasificaciones y los ejemplos -encontrados en el anexo-son fácilmente reconocibles en el ámbito nacional e internacional.

Como aspecto original podemos resaltar el tratamiento que se hace en este estudio del turismo dark en la realidad turística española para lograr fijar las bases de un modelo más sólido de identificación, caracterización y clasificación del amplio espectro del turismo dark. En este sentido, existe cierta ambigüedad y una ausencia de consenso sobre qué es y qué ha de ser catalogado como turismo dark, de manera que esta investigación recopila de forma sintética y nuclear toda la terminología asociada al turismo dark. Y, asimismo, se ha intentado caracterizar tanto la evolución, la conceptualización como las clasificaciones clásicas del turismo dark, a partir de las cuales se ha planteado un nuevo modelo de clasificación propuesto que entendemos mucho más completo. 
Como argumentan Ashworth e Isaac (2015), nos encontramos en un momento en que el turismo dark o los sitios dark (black spot) pueden tener una demanda real y/ potencial nada desdeñable en destinos turísticos muy diferentes entre sí y ciertamente numerosos. En consecuencia, resulta necesario clasificar, identificar y catalogar todos aquellos recursos territoriales, escenarios y productos que pueden asociarse al turismo dark, así como en el caso de España, reconocer las potencialidades de esta modalidad turística a través del análisis de casos y experiencias prácticas. Por añadidura, se ha pretendido elaborar con este estudio el primer recopilatorio que ejemplifique categorías principales, secundarías y subcategorías de los lugares y escenarios susceptibles de desarrollar productos y actividades asociados al turismo dark, y a partir de aquí poder diseñar un espectro dark o darkmeter con criterios objetivos para clasificar e identificar los enclaves que le sirven de soporte.

Por último, se ha intentado establecer algunas orientaciones para la valorización turística de los recursos territoriales dark en la industria turística española, analizar la posible estigmatización de la demanda en determinados ámbitos de opinión pública, identificar los obstáculos para su desarrollo y mejorar las técnicas de marketing, la factibilidad y la rentabilidad del turismo dark en la oferta turística en España como país líder en competitividad turística mundial según la WEF, aunque aún poco diversificado y anclado en el turismo clásico y de masas como el de sol y playa. Para ello, se han seguido principalmente las líneas de investigación y aportaciones de Sharpley sobre la demanda y la oferta del turismo dark (Sharpley y Stone, 2009a).

\subsection{Objetivos, hipótesis de partida y proceso de verificación}

Los objetivos y las hipótesis iniciales planteadas, que se encuentran concatenados entre sí, han sido los que a continuación se relaciona:

- Objetivo 1: Definir el concepto de turismo oscuro desde sus orígenes, sus cambios evolutivos, sus criterios terminológicos y sus clasificaciones clásicas, además de sus características.

Subobjetivo 1: Diseñar un cuadro clasificatorio internacional con un centenar de ejemplos de recursos territoriales dark explotados o por explotar.

- Objetivo 2: Analizar los obstáculos que limitan la comercialización del turismo dark en la realidad concreta de España como país líder en competitividad turística mundial.

- Subobjetivo 1: Analizar las características y elaborar un diagnóstico de las motivaciones de los consumidores dark.

- Subobjetivo 2: Perfilar un análisis del tratamiento dark en otros países, sus estrategias de marketing aplicado y sus niveles de rentabilidad.

- Objetivo 3: Creación ad hoc de un nuevo cuadro clasificatorio por niveles de intensidad del turismo dark.

- Objetivo 4: Obtener conclusiones y resultados capaces de apuntar las bases de la posible gestación de proyectos de empresas y destinos sostenibles de turismo dark en la oferta turística española.

- Hipótesis I: La diversificación de los productos turísticos es consecuencia directa de una nueva generación de turistas mucho más críticos, exigentes e influenciables en las redes sociales y nuevos instrumentos de promoción y comercialización turísticas. No obstante, 
aunque existen recursos dark en España que pudieran permitir el desarrollo de nuevos productos turísticos, el turismo dark no es fácilmente extrapolable al mercado turístico español. Es decir, aunque a nivel teórico la factibilidad del turismo dark exista, ésta no implica necesariamente que los casos de éxito existentes puedan extrapolarse en la practica per se en cualquier destino.

En este sentido, se analiza en este trabajo el principal motivo que puede obstaculizar esta práctica al mercado turístico español, partiendo de la consideración de la propia complejidad del fenómeno y su heterogeneidad de sus manifestaciones, así como de los propios condicionamientos legales sobre el desarrollo de la cultura turística dark, como los ya existentes en países pioneros como Estados Unidos.

- Hipótesis II: En España el turismo dark no ha superado aún los prejuicios y barreras de lo "políticamente incorrecto", de manera que no se ha desprendido del estigma de su considcración como actividad oscura, clandestina y vergonzante que cubre una "sed mórbida" y malsana. En consecuencia, si no hay un componente histórico-cultural claro que sustente de manera principal el turismo dark, su consumo va a seguir estando estigmatizado negativamente.

Este estigma analizado para el caso de España, se considera un gran obstáculo en el desarrollo de esta modalidad turística y, como resultado, resulta necesario entender la envergadura del mismo y qué lo motiva. Para rechazar o verificar la hipótesis de forma taxativa, se establecieron tres tests de verificación complementarios entre sí, a saber:

- Test 1: Una encuesta. Preguntas concretas a un colectivo heterogéneo de personas relacionadas con el consumo de productos turísticos o con profesionales del sector.

- Test 2: Estudios de referencia. Conjunto de aportaciones e ideas procedentes de los estudios específicos sobre turismo dark.

- Test 3: Entrevistas a profesionales. Opiniones de profesionales relacionadas con la industria turística en nuestro país y sus valoraciones respecto al turismo dark en España.

Las antedichas hipótesis resultaron verificadas y se entendieron como aceptadas al no encontrarse discrepancias importantes entre los tres filtros establecidos.

\section{Concepto y orígenes}

Aunque el concepto de turismo dark pueda remontarse a varios siglos atrás, la popularidad y el interés en las últimas décadas por su consumo han fomentado la proliferación de algunos estudios académicos rigurosos y pioneros. Los más significativos fueron en primer lugar, los de Lennon y Foley, quienes acuñaron por primera vez el término de turismo dark a finales de los años noventa. Con posterioridad, Seaton comienza a utilizar el término como tanatoturismo y, finalmente, es Rojek quien desarrolla el concepto de "lugares negros (black spots) (Yuill, 2003).

Por lo que se refiere al concepto de turismo dark y tanatourismo ${ }^{2}$, a priori, la literatura científica es tremendamente confusa y no aclara si son términos diferentes o partes integrantes del mismo concepto. El turismo dark se ha venido utilizando como un término inclusivo general

\footnotetext{
2 El término "tanatoturismo" toma su raíz del griego, thanatos (que significa muerto o muerte), para describir el turismo en lugares que se asocian principalmente con la muerte. Si bien se llama "turismo de duelo", "turismo mórbido" y, con mayor frecuencia, "turismo oscuro" o "turismo dark" (Seaton, 2009). Para Liviano es un oxímoron donde se utilizan dos conceptos con significado opuesto en una misma expresión. En este caso, "el placer y el disfrute, y el dolor, el sufrimiento y la muerte" (Liviano, 2019).
} 
para cualquier forma de turismo relacionado con la muerte, con el sufrimiento, las atrocidades o los crímenes y esta idea conceptual se comienza a forjar a finales del siglo XX. En cambio, el tanatoturismo parece $a b$ initio para la comunidad académica como un concepto mucho más específico que versa sobre las prácticas de viaje motivadas por un impulso o deseo de encuentro con la muerte. En cualquier caso, los elementos vertebradores son turismo y muerte.

Como se apuntaba anteriormente, aunque se haya popularizado, comercializado y conceptualizado el turismo dark en las últimas décadas, las visitas a los lugares vinculados a la muerte, a los campos de batalla o a las atrocidades se han venido practicando en el campo religioso desde la Antigüedad. Las visitas a los cementerios fueron una imperiosa obligación para muchas religiones. Esta tesis también ha sido mantenida por Collins-Kreiner (2016), quien también vincula claramente el turismo dark con una peregrinación dramática sobre eventos históricos y con una simbología ${ }^{3}$ entorno a la muerte.

Aunque Foley y Lennon son los pioneros en acuñar el término de turismo dark en los noventa, Kazalarska (2002) es el primero que defiende la atemporalidad del concepto y añade que la atracción por la muerte y el desastre siempre ha sido y será un detonante y una motivación para viajar. Para ello se retrotrae hasta la Antigüedad donde fundamenta el interés y la atracción por los lugares dark en las peregrinaciones y la muerte de individuos de importancia religiosa y mística. Incluso un primer ejemplo "moderno" de turismo dark lo encontramos en la Inglaterra del siglo XVII, donde se organizaban encuentros para presenciar las ejecuciones públicas o en la Francia del siglo XIX donde se popularizaron las visitas a las morgues en París o las escapadas para presenciar las muertes por guillotina.

Stone recoge el testigo de los orígenes que marcaba Kazalarska y directamente los enmarca en escenarios de guerras, cementerios, campos de concentración, catacumbas, lugares de asesinatos, escenarios de fenómenos paranormales y otros desastres provocados por el hombre e, inexorablemente, relacionados con la muerte. Claramente Stone habla por primera vez de importantes atracciones turísticas relacionadas con la muerte, de interés por el destino oscuro y por la mercantilización de un producto turístico macabro. Dicho concepto pronto derivó en una incipiente modalidad turística llamada turismo $\operatorname{dark}^{4}$ (Stone, 2005).

\section{1. Las clasificaciones clásicas del turismo dark}

Stone también es el primero que advierte sobre la proliferación de diferentes subtipologías vinculadas con la actividad turística y la muerte. Dicha consideración dio lugar a múltiples etiquetas como "vacaciones en el infierno", "turismo mórbido", "turismo de puntos negros" o aliterados como "milking the macabre", generando la falsa idea de una heterogeneidad de la actividad (Stone, 2005).

Por otro lado, la clasificación del turismo dark es también un tema muy poco consensuado en el ámbito de la comunidad científica y profesional del turismo. Aunque muchos interpretan el turismo dark como una parte integrante de las atracciones del turismo cultural (Richards, 2001), lo cierto es que no existen estudios sobre la relación entre ambos (Hughes, 2002). Lo que sí comienza a surgir de la mano de Stone es la idea de un espectro de intensidad en el

\footnotetext{
${ }^{3}$ Algunos autores comentan que el turismo dark es muy vulnerable a las críticas y que se desarrolla rápidamente un proceso de "kitschnificación" (de mal gusto) hacia la comercialización de recuerdos trágicos (Sharpley y Stone, 2009b).

${ }^{4}$ El inicio moderno del turismo dark podría entenderse desde los ataques terroristas en la ciudad de Nueva York el 11 de septiembre de 2001. En la actualidad, miles de estadounidenses y extranjeros emprenden un peregrinaje a las cataratas que conmemoran la muerte de 3.000 personas en el World Trade Center (Remenyik, 2014).
} 
turismo dark. Es decir, que determinados enclaves pueden ser concebidos como "más oscuros" que otros a raíz de varios parámetros, características o percepciones (Stone, 2006).

Anteriormente, Miles ya había argumentado que existe una clara distinción entre los enclaves oscuros y muy oscuros (dark and daker tourism) y considera que la semántica es importante en la clasificación para diferenciar entre macabro (macabre) y lúgubre (morose) (Miles, 2002). Igualmente, en función de la dimensión temporal y la afinidad con un enclave, se distinguen entre lugares relacionados con la muerte y el sufrimiento,y sitios que per se son de muerte y sufrimiento.

En conclusión, para Miles una visita a un lugar relacionado con la muerte es turismo dark y un viaje, una excursión o una peregrinación a un lugar de muerte es un grado superior, en ese espectro oscuro, ergo entendido como “darker tourism” (Miles, 2002).

Para Seaton (1996), el turismo dark se puede clasificar en cinco grandes categorías:

- Actos públicos de muerte: principalmente castigos y sentencias capitales derivados de la aplicación de la ley islámica o sharia.

- Evidencias o representaciones simbólicas de la muerte o exhibiciones que recrean eventos: la tragedia de Pompeya.

- Monumentos conmemorativos como cementerios o memoriales de guerra. Cementerios como los judíos, memoriales de atentados terroristas o de genocidios.

- Reconstrucciones o representaciones de la muerte: festivales de temática religiosa en sus inicios hasta las batallas por clanes.

- Lugares donde han ocurrido muertes individuales o en masa: principalmente campos de genocidio como los de Camboya, Ruanda o Polonia. También incluyen lugares de crímenes atroces como los de la mansión donde el criminal sectario Charles Manson ordenó asesinar a varias celebridades.

Otra clasificación importante fue la que aportó Dann (2000), que propone seis categorías:

- Los lugares de asesinatos en masa, atentados y genocidios: Camboya.

- Los museos asociados a la muerte (p.ej.: el museo de la Segunda Guerra Mundial de Estrasburgo).

- Visitar cementerios y memoriales: Memorial del holocausto judío (Berlín).

- Acudir a Mazmorras por placer: el castillo de Špilberk (República Checa).

- El turismo bélico o de batallas: Pearl Harbour (EE.UU.)

- El turismo de esclavitud: lugares donde los esclavos fueron encerrados para ser explotados posteriormente. P.ej.: el Cape Coast, en la actual Ghana.

Posteriormente, Lennon y Foley (2000) establecen una nueva clasificación en seis grandes grupos turísticos para el turismo dark:

- El turismo de campo de batalla: La batalla del Ebro (España).

- El turismo de cementerio: El cementerio Nacional de Arlington (EE.UU.).

- El turismo de desastres y tragedias: La tragedia de Bhopal (India) o Chernóbil (Kiev).

- El turismo de fantasmas: El más famoso sería el de Escocia.

- El turismo de holocausto: destacan el del Congo, Ruanda, Armenia, Camboya o Polonia.

- El turismo de prisión: la prisión de Alcatraz. 
Finalmente, es Stone (2006) el que realiza la clasificación del turismo dark más completa, ambiciosa y comúnmente aceptada en la comunidad académica que estudia la materia. Por adición, Stone es el primero que establece un espectro de intensidad que abarca desde lo "suave" hasta lo "fuerte" o incluso de nivel "impactante y extremo". Bajo esta interpretación, Stone alumbra las siguientes siete categorías, que se han dotado de sendos ejemplos para una mejor asimilación.

1. Fábricas de entretenimiento (Dark Fun Factories): Básicamente están asociadas a visitas centradas en el ocio y el entretenimiento donde se representa a la muerte de forma ficticia y se recrean escenarios y eventos trágicos y macabros con fines lucrativos. Los ejemplos más claros serían el London Dungeon, el castillo de Bran en la región de Transilvania en Rumanía donde se recrea la ficción del Conde Drácula, por la novela de Bram Stoker, con el príncipe Vlad Tepes (Vlad el Empalador). Stone lo califica como "diversiones enlatadas" (Stone, 2006).

2. Exposiciones (Dark Exibitions): Englobaría a todos los productos que se relacionan con la muerte y que mantienen una orientación conmemorativa, educativa o crítica, aunque bajo un prisma claramente comercial. Existen varios ejemplos relevantes como la controvertida exposición mundial con cadáveres reales "Body worlds" o el Museo Memorial de la Paz de Hiroshima, el lugar de conmemoración en el Parque de la Paz.

3. Mazmorras (Dark Dungeons): principalmente se refieren a prisiones subterráneas que son usadas con carácter educativo y de entretenimiento. Estos lugares tratan de mostrar los códigos de justicia empleados en épocas pasadas. Por ejemplo, la cárcel del centro de Bodmin en Cornwall (Reino Unido), donde los consumidores se sienten atraídos por las historias de las cámaras, allí los prisioneros fueron torturados por mala conducta. Similares son las galerías de Nottingham (Reino Unido) bajo el lema "feel the fear" (siente el miedo), el Old Merlbourne Gaol (Australia) donde los consumidores dark pueden observar una colección de máscaras mortuorias de presos, hasta ejemplos más contemporáneos como la antigua prisión Robben Island (Sudáfrica) donde Nelson Mandela estuvo encarcelado.

4. Lugares de descanso (Dark Resting Places): fundamentalmente se hace alusión a los cementerios. Éstos son entendidos como un instrumento utilizado por los dinamizadores turísticos para potenciar y fomentar la visita del área, conservar la integridad del entorno y su arquitectura. Adicionalmente, se consideran como un elemento conmemorativo. Ejemplos reseñables son el cementerio de Père Lachaise en París, que cuenta con varios millones de visitantes anuales cautivados por la arquitectura de inicios del siglo XIX, y con tumbas célebres como las de Oscar Wilde o María Callas. Igualmente, el archiconocido Hollywood Forever Cemetery (Estado Unidos) que dispone de los restos de celebridades tales como Alfred Hitchcock o Rita Hayworth.

5. Santuarios (Dark Shrines): se ubican en el lugar de la tragedia para rendir homenaje, respeto y conmemorar a las víctimas. Nacen con una escasa infraestructura turística y, normalmente, por un periodo corto de tiempo. La temporalidad del santuario depende de la repercusión mediática y política del infortunio. Los ejemplos más significativos son: el edificio de flores situado en la entrada principal del palacio de Kensington en memoria de la princesa Diana de Gales o el recinto de velas a las víctimas del ataque terrorista en Barcelona el pasado 17 de agosto de 2017. No obstante, también existe la posibilidad de lugares más permanentes como es el caso de la Zona cero en Nueva 
York que conmemora el fallecimiento de miles de personas que murieron como consecuencia de los ataques terroristas del 11S.

6. Enclaves de conflictos bélicos (Dark Conflict Sites): Son lugares que giran alrededor de actividades relacionadas con conflictos, batallas y guerras. Cuentan con grandes infraestructuras turísticas y mantienen un propósito educativo, conmemorativo o histórico. Existen operadores turísticos que comercializan la recreación de batallas como la Batalla de Bosworth (Reino Unido), las de las playas de Normandía, al noroeste de Francia, durante la Segunda Guerra Mundial, o la Colina del León de Bélgica donde se conmemora la Batalla de Waterloo. Aunque muchas veces caen con frecuencia en una excesiva versión romántica de sucesos que son sangrientos y trágicos.

7. Campos de genocidio (Dark Camps of Genocidice): Es la categoría más oscura (dark) de todas las de Stone. Abarca los campos de concentración donde sucedieron genocidios, holocaustos, exterminios, graves torturas y atrocidades. Su ubicación corresponde al lugar donde sucedieron las muertes y, aunque no todos cuenten con una gran infraestructura turística desarrollada, el número de visitantes es abrumador. Además, mantienen un alto grado histórico, educativo y conmemorativo para no caer en frivolidades innecesarias. El ejemplo más conocido y símbolo universal es el campo de concentración de Auschwitz Birkenau (Polonia) donde fallecieron más de un millón de judíos como consecuencia del régimen nazi. Otros destacables son el de Mauthausen Gusen (Austria) o los de Camboya, Kosovo o Ruanda.

\section{Análisis de las motivaciones de los consumidores dark}

La motivación turística ha sido siempre una incógnita más que resolver en la ecuación de la industria, pero sobre todo es un elemento esencial en la investigación turística. Existen tantos matices que las motivaciones parecen configurarse como un elemento complejo en todas las tipologías del turismo, pero sin ellas, en todo caso, los visitantes no podrían categorizarse en términos demográficos, socioculturales, ideológicos, económicos y otros muchos factores. Tal y como apuntan Woodside y Martin (2008), resulta muy difícil entender e identificar el por qué los turistas "actúan como actúan. Sin embargo, en el pasado se instaló una definición de motivación turística que prevalece aún hoy día en la comunidad académica como red general e integradora de las fuerzas culturales y biológicas que ofrecen valor y dirección a las variantes del viaje, a la experiencia y al comportamiento (Pearce, Morrison, Alastair y Rutledge, 1998; Rivera, 2013).

En primer lugar, es conveniente recalcar que en el turismo dark la muerte es una característica inherente a la propia condición humana. Todo este planteamiento ha causado la imperiosa necesidad de desarrollar instrumentos o mecanismos mentales para poder enfrentarse a la idea de que, más tarde o más temprano, todos nosotros dejaremos de existir. Puede, incluso, que esa misma preocupación haya sido la razón fundamental por la que las personas han estado vinculadas y atraídas por los enclaves y los eventos relacionados con el desastre, el sufrimiento, la violencia y la muerte. Como casos históricos reseñables podemos citar, por ejemplo, las luchas de gladiadores en el circo romano o la asistencia a las ejecuciones medievales.

En este punto, se destaca una de las opiniones procedentes de las entrevistas realizadas en esta investigación. En concreto, la del profesor de la Universidad Oberta de Cataluña (UOC), Daniel Liviano, que afirma lo siguiente: "una parte importante de los tanatoturistas tiene la necesidad de conectar de una manera simbólica y espiritual con la muerte, y este hecho trasciende a cualquier religión. Así, una persona puede no ser creyente, en el sentido de que no 
profesa ninguna fe en ninguna religión en particular y, aún así, necesitar afrontar la idea de la muerte. Viajar es simplemente una manera de hacerlo".

Está claro que en las últimas décadas el perfil del turista ha cambiado hacia un carácter más crítico, exigente, influenciable e hiperconectado en búsqueda de lo auténtico, lo genuino lo propio, lo personalizado, lo sui generis, lo bizarro pero, exactamente, ¿qué se esconde detrás de un consumidor dark? (Goossens, 2000; Arellano, Rivera y Molero, 2013). Pero el principal problema de la motivación turística, específicamente en las relacionadas con las del turismo dark, es que existe un decalaje importante e insalvable entre lo que la gente hace y lo que verdaderamente piensa, originado quizás por la poca familiarización que tenemos sobre nuestras propias emociones. Adicionalmente, también existen casos en los que se camuflan las intenciones y las motivaciones reales con el propósito de salvaguardar nuestros propios intereses (Woodside y Martin, 2008).

En general, se puede advertir que las motivaciones están fragmentadas en tres grandes grupos. El primer grupo estaría compuesto por visitantes con un interés bajo en la temática y que se encuentran con un enclave dark de manera ocasional a raíz de un viaje con otros propósitos. En el segundo grupo, los visitantes que buscan dar sentido a lo que consideran auténtico y genuino, y acuden a enclaves que no pretenden perfilarse como una atracción per $s e$. Finalmente, el tercer grupo haría referencia a visitantes que de forma intencionada buscan esos lugares y viajan a ellos, y que, por adición, están configurados como atracciones turistas (Sharpley y Stone, 2009a).

Durante las últimas décadas, varios autores han ido planteando diferentes motivaciones que ayudan a definir, de una forma más precisa, las motivaciones que podrían subyacer en la práctica del turismo dark. Entre ellas, y a modo introductorio, destacan: la afición por los acontecimientos históricos, la necesidad de rendir honores, el entretenimiento, la simbología, la curiosidad y satisfacción por lo inusual, como válvula de escape, la autenticidad o, incluso, el placer en ver y disfrutar con la desgracia ajena.

Mientras que para Lennon y Foley el énfasis se debe colocar en la capacidad básica de relacionar la naturaleza de las visitas a lugares relacionados con los desastres y las catástrofes (Lennon y Foley, 2000), para Stone los condicionantes de la motivación hacia el turismo dark están claramente asociados a factores socioculturales con la mera finalidad de que los visitantes puedan encontrarse a sí mismos (Stone, 2006).

No obstante, otros autores ofrecen nuevas interpretaciones sobre las verdaderas motivaciones. Algunos sostienen la tesis de que los turistas dark se encuentran en una búsqueda periódica hacia nuevas experiencias, porque les resulta imprescindible escapar de la rutina y la monotonía diarias. Otros consideran que, en ocasiones, el carácter histórico, el prestar las condolencias y rendir honores y el respecto y consideración hacia personas del pasado puede llegar a ser la principal motivación del desplazamiento más allá del mero entretenimiento (Yuill, 2003). Incluso, se hacen interpretaciones más filosóficas, como la de Stone, que entiende que hacer turismo dark es entender y aceptar mejor el proceso que implica la muerte y naturalizarla, o Chang (2014), que considera que los motivos tienen un componente e interpretación cultural que implican aliviarse de cierta presión y tensión psicológica.

Otras motivaciones justifican las visitas a los enclaves dark por el entretenimiento y el ocio ligados al conocimiento de la historia y la cultura, aunque no sean necesarios vínculos totalmente directos, como, por ejemplo, en el conocimiento y aprendizaje de estrategias militares a través de detalles sobre batallas históricas (Smith, 1996). Siguiendo la estela de dicha motivación, se incluiría igualmente a todas aquellas personas sensibilizadas y sugestionadas con la muerte o la tragedia y que desean conocer el origen de un evento o enclave destacado 
por su simbología e identidad y ligados a veteranos de guerra, supervivientes o descendientes y al círculo íntimo de los mismos (Korstanje e Ivanov, 2012).

En cualquier caso, los impactos de la muerte y la tragedia generan una onda expansiva que abarca mucho más allá de los supervivientes, como en el caso, por ejemplo, de los campos de concentración. En ellos, un gran número de personas se sienten poderosamente atraídas por los puntos de turismo oscuro debido a las repercusiones humanas y sociales que tuvo un hecho histórico concreto, por la afiliación personal directa o indirecta con el suceso o por la sensibilidad para interpretar y entender el sufrimiento (Biran, Poria y Oren, 2011; Norrild, 2007).

En otras ocasiones, los motivos se dirigen hacia la mera curiosidad y la satisfacción por lo inusual, lo insólito, lo excepcional y por la diversión experimentando lo horrible, incluyendo además nuevos conceptos como la autocomprensión, la búsqueda de la propia identidad o el interés en el sufrimiento y la violencia (Hartmann y Ashworth, 2005). Otros se sienten arrastrados por la moda de una actividad novedosa que pueda ser una válvula de escape a la rutina y al aburrimiento. Y relacionado con el escapismo del entorno habitual, se encontraría también la búsqueda de la aventura, de lo complejo, de la incertidumbre y, en consecuencia, la activación de la adrenalina y la hiperexcitación.

Seaton y Lennon (2004) van más allá e incluso lo relacionan con el placer en ver y disfrutar con la desgracia de lo ajeno y con la contemplación de la muerte aludiendo al término alemán "schadenfreude"5 o al español epicaricacia ("regodeo") (Seaton y Lennon, 2004). Algunos puntos de vista principales acerca de los motivos que pueden mover a las personas a realizar turismo dark se reflejan en la Tabla 1 siguiente:

Tabla 1: Resumen y cronología de las motivaciones del turista dark por autor.

\begin{tabular}{lll}
\hline \multicolumn{1}{c}{ MOTIVACIONES } & AUTORES & \multicolumn{1}{c}{ EJEMPLOS } \\
\hline $\begin{array}{l}\text { Aprender lecciones pasadas y evitar } \\
\text { repetirlas. }\end{array}$ & (Seaton, 1996) & $\begin{array}{l}\text { Lugares de esclavitud, campos } \\
\text { de concentración }\end{array}$ \\
$\begin{array}{l}\text { Buscar experiencias fuertes y desear vivir } \\
\text { unas "vacaciones en el infierno". }\end{array}$ & (Dann, 1998) & $\begin{array}{l}\text { Prisiones, lugares de } \\
\text { catástrofes o cementerios. }\end{array}$ \\
$\begin{array}{l}\text { Ganas de cambiar la percepción sobre la } \\
\text { mortalidad. }\end{array}$ & (Pelton, 2003) & $\begin{array}{l}\text { Rituales y ceremonias sobre la } \\
\text { muerte. }\end{array}$ \\
$\begin{array}{l}\text { La imperiosa necesidad de tener una } \\
\text { confrontación con la muerte y con lugares } \\
\text { violentos y oscuros. }\end{array}$ & (Stone y & $\begin{array}{l}\text { Lugares de holocausto, y de } \\
\text { esclavitud. }\end{array}$ \\
$\begin{array}{l}\text { Cubrir nuestras necesidades morbosas y } \\
\text { saciar la curiosidad. }\end{array}$ & (Moufakkir y & $\begin{array}{l}\text { Prisiones, lugares de } \\
\text { catástrofes o cementerios. }\end{array}$ \\
$\begin{array}{l}\text { Mostrar interés en los recuerdos y en } \\
\text { eventos históricos que han producido } \\
\text { sufrimiento y mortandad. }\end{array}$ & Burns, 2012) & $\begin{array}{l}\text { Lugares de esclavitud y } \\
\text { enclaves de genocidio }\end{array}$ \\
$\begin{array}{l}\text { Conservar el patrimonio y ayudar a } \\
\text { mantener la identidad de un colectivo. }\end{array}$ & (Yuill, 2003) & $\begin{array}{l}\text { Campos de concentración o } \\
\text { memoriales. }\end{array}$ \\
\hline
\end{tabular}

${ }^{5}$ Schadenfreude es una palabra de origen alemán que denota el sentimiento de alegría o satisfacción generado por el sufrimiento, la infelicidad o la humillación de otro. El término más similar en español es epicaricacia. 
El deseo personal de rendir honores.

Conocer lugares famosos relacionados con la muerte.

Visitar lugares que se consideran imprescindibles. Seguir la cultura de los "must visits" o del "bucket list".

Las visitas que se engloban en un itinerario turístico organizado más amplio.
Lelo y Jamal

(2011)

Cheal y Griffin

(2013)

Hyde y

Harman (2011) de genocidio
Lugares de esclavitud

Lugares de holocausto y campos de batalla

Brown (2016) Prisiones o cementerios

\section{Fuente: Elaboración propia}

En conclusión, las motivaciones dependen del conocimiento, de la educación, de los vínculos e interrelaciones, de los gustos, y del grado y la escala de importancia que tengan presentes los turistas. La motivación es múltiple y no necesariamente única ni contradictoria, puede existir un conjunto de motivaciones que retroalimenten el interés en la práctica del turismo dark. Son tantas las motivaciones interrelacionadas como las formas, siempre únicas, que genera un caleidoscopio.

\section{Metodología}

La metodología empleada para esta investigación sobre el turismo dark ha sido variada, en función del recurso objeto de estudio y de las conclusiones que se pretenden obtener. Para ello, se ha utilizado una metodología cuantitativa y cualitativa estructurada por una serie de etapas que han tratado de cimentar y apuntalar los objetivos prefijados, además de poder ofrecer respuestas a las hipótesis planteadas y obtener finalmente unas conclusiones y lecciones aprendidas capaces de generar un cierto consenso en la escasa comunidad académica que ha tratado o profundizado en este tema con cierto rigor en España.

Por un lado, con la investigación cualitativa se pretendió extraer, mediante una observación participante y exploratoria, datos de cierta entidad y profundidad de forma inductiva y holística que pudieran complementar la investigación cuantitativa. Por contraste, con la investigación cuantitativa se obtuvo una información más objetivable y empírica y con una base más deductiva y particularista, con mediciones estadísticas controladas que sirvieron para cuantificar y poder extraer conclusiones más fidedignas (Ugalde, 2013).

Para mantener una línea general de investigación para obtener resultados globales e integrales y plantear una visión de la misma orientada hacia la planificación estratégica del fenómeno de estudio en España, se ha decidido vertebrarla en diferentes etapas y aplicar en cada una unas herramientas metodológicas específicas:

- Etapa 1: El interés por el mercado dark en España.

- Etapa 2: El diseño de producto y las modalidades de turismo dark en España.

- Etapa 3: La confección de un nuevo espectro dark (El darkmeter).

Para la primera etapa, el interés por el mercado dark en España, se empleó una doble metodología. Por un lado, una metodología cualitativa en forma de entrevista a un colectivo profesional configurado por un elenco variado de escritores, investigadores, guías de turismo y profesores relacionados con la industria turística y, por el otro, una metodología cuantitativa a una muestra heterogénea y representativa de 100 turistas y viajeros con diversos grados de conocimiento o experiencias sobre el tema de estudio. En la metodología cualitativa los datos 
se recopilaron mediante el análisis de las entrevistas y su tabulación mediante observación directa, mientras que con la metodología cuantitativa, los datos se tabularon en forma de tablas y gráficos interpretativos. El elenco de entrevistados ha estado integrado por:

- Un profesor de la Universidad Oberta de Cataliña (UOC) especialista en tanatoturismo ${ }^{6}$ $\mathrm{y}$ un viajero amateur.

- Un profesor de economía y empresa en la Universidad Oberta de Cataluña (UOC).

- Un guía turístico y conocedor de la industria de los viajes.

- Un escritor, bloguero e influencer del sector de los viajes.

- Una CEO de la agencia de viajes Sevilla4Real.

Para la segunda fase de la investigación, el diseño de producto y la caracterización de la tipología dark, se tomaron como referencia las clasificaciones básicas y clásicas de Dann, Seaton, Foley y Stone ya citadas con anterioridad. Específicamente, el legado de Stone se empleó como base para ampliar, ejemplificar y reformular la nueva clasificación elaborada mediante una investigación cualitativa y la observación empírica. El cuadro de clasificación que se creó ad hoc ha generado una primera herramienta técnica que ha facilitado unas pautas para una correcta identificación, clasificación y categorización de los recursos territoriales que sirven de soporte y cualificación al turismo dark en España. Su finalidad ha tenido una orientación aplicada a la gestión pública de los destinos de turismo dark a través de sus organizaciones de gestión como los Patronatos Provinciales de Turismo, Areas de Turismo de las entidades locales o empresas públicas y consorcios de turismo, con el objetivo de que puedan identificar enclaves y recursos territoriales con potencialidades de servir de base para el diseño de paquetes turísticos dark que, al menos, complementen, diversifiquen y enriquezcan la oferta turística preexistente. Y con esto se ha pretendido concienciar sobre la necesidad de ir realizando un inventario para los planificadores y gestores de los espacios turísticos interesados en el turismo dark, así como definiendo una serie de pautas homogéneas para identificar, evaluar, jerarquizar o clasificar dichos recursos turísticos para fomentar la creación de productos de turismo oscuro.

Para la tercera etapa de la investigación, por último, la confección de un nuevo espectro dark (el darkmeter) se formuló una encuesta de finalidad experimental a un colectivo heterogéneo de personas relacionadas con el sector turístico en general. En ella, los encuestados clasificaron y valoraron los niveles de intensidad de las experiencias de turismo oscuro en cuatro grandes categorías (A, B, C y D), mediante expresiones e imágenes que sintetizaran dichos niveles a partir de una escala en la que 1 es el valor de menor intensidad dark y 4 la de mayor intensidad y más propiamente característica del turismo dark. A posteriori, se tabularon finalmente los datos del experimento en tablas y, en consecuencia, se definió un nuevo espectro dark más completo y creemos que más real que los que se habían definido en la literatura científica y profesional hasta la fecha.

\section{El Darkmeter. La creación de un nuevo espectro clasificatorio de los niveles de intensidad el turismo dark}

La elaboración del darkmeter o el nuevo espectro dark forma parte de uno de los objetivos prefijados en este trabajo de investigación. El darkmeter como elemento de innovación en la

\footnotetext{
${ }^{6} \mathrm{La}$ Tanatopraxia hace referencia a un conjunto de prácticas que se efectúan sobre un cadáver desarrollando y aplicando métodos destinados a su higienización, conservación, embalsamamiento, restauración, reconstrucción y cuidado estético del cadáver.
} 
investigación pretende aportar una herramienta útil a la comunidad académica que ha categorizado el turismo dark para su mejor caracterización y para la identificación de sus variables internas, partiendo de que, en realidad, existen algunas categorías que hasta la fecha no habían sido clasificadas e identificadas en las subtipologías clásicas de turismo dark. Además, también existen valores a tener en cuenta para generar una nueva interpretación del grado de intensidad de los recursos territoriales y enclaves de turismo dark, con el objeto de conseguir un mejor entendimiento de este fenómeno y asentar las bases el diseño de productos y la promoción y comercialización de éstos a través de rutas e itinerarios de turismo dark en España.

El darkmeter conllevó un doble esfuerzo en paralelo. Por un lado, la confección de las categorías dark exigió la realización de un barrido previo de referentes y experiencias de turismo dark en el mundo y una posterior clasificación y subclasificación de los mismos. Para ello se utilizaron siete categorías básicas y clásicas ("The seven dark suppliers") propuestas por Stone, que propuso una serie de condicionantes que, a su juicio, infieren en la clasificación clásica de los recursos territoriales turísticos y los enclaves de turismo dark. En ellas se aprecian, fundamentalmente, parámetros e indicadores como los factores políticos, ideológicos y sociales y los más intrínsecamente asociados a la muerte y el sufrimiento.

Siguiendo los pasos de Stone, se ampliaron los parámetros e indicadores considerados como los de carácter temporal, el generacional o el cultural, de manera que se reformularon hasta un total de cuatro grandes categorías (a, b, c y d) y se establecieron hasta veinte categorías principales y múltiples subcategorías secundarias mediante la observación empírica, los resultados de la investigación cualitativa y el análisis de las experiencias y estudios de caso analizados en la revisión de la literatura.

Bajo la premisa anterior, se logró gestar el primer espectro de intensidad de los recursos turísticos dark que pueden integrarse en las veinte subcategorías finalmente identificadas. A través de la encuesta antes referida a una población heterogénea de 100 personas, se ha podido generar un espectro o grado de intensidad dark bastante significativo. Con los datos tabulados de la encuesta se ha confeccionado ad hoc una tabla que representa nítidamente los distintos niveles de intensidad y un nuevo orden de categorías y subcategorías de los recursos territoriales dark (Tabla 2).

Tabla 2: Tabla elaborada con las categorías principales (A, B, C y D), las categorías secundarias (1-20) y las múltiples subcategorías secundarias de los recursos dark.

\begin{tabular}{|c|c|c|}
\hline & Categoría secundaria & Subcategoría secundaria \\
\hline 1 & Fábricas de entretenimiento & Parques temáticos y espectáculos de terror \\
\hline 2 & Lugares de ficción & Sets de películas de terror/Enclaves de fama \\
\hline 3 & Eventos y congregaciones & Festividades de la muerte \\
\hline C. A 4 & Enclaves de conflicto & $\begin{array}{l}\text { Escenarios bélicos (búnkeres, túneles, } \\
\text { trincheras, fortificaciones, fortines, } \\
\text { refugios...) }\end{array}$ \\
\hline 5 & Lugares de descanso & $\begin{array}{l}\text { Panteones, cementerios, mausoleos, } \\
\text { monumentos funerarios... }\end{array}$ \\
\hline 6 & Santuarios especiales & Veneración a ídolos fallecidos \\
\hline
\end{tabular}




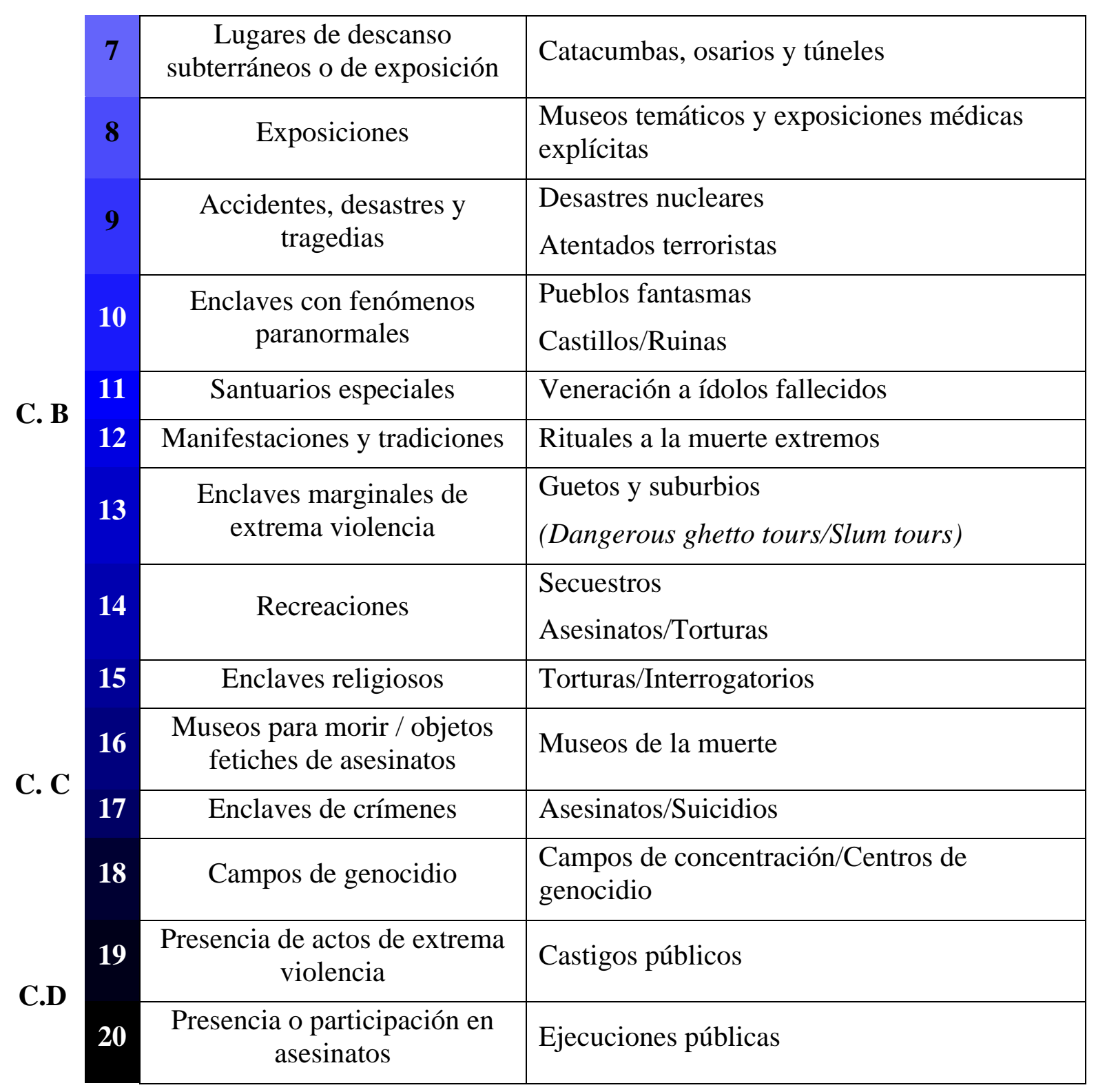

Fuente: Elaboración propia

\section{Enfoques del turismo dark desde la óptica del marketing y de la demanda}

Los viajes experienciales y relacionados con enclaves dark podrían suponer una "revolución" en la forma de asimilar la cultura, la historia y de entender mejor las necesidades sociales (O' Shaughnessy, 1991). No obstante, es necesario advertir que la comercialización del turismo dark es toda muy embrionaria, es decir, no existen antecedentes importantes de mercantilización en Europa y menos aún en España. Además, el turismo dark implica una innovación creciente en el terreno de los viajes, al cubrir necesidades insatisfechas originadas por una demanda turística muy particular y genuina, aunque no importante aún desde el punto de vista cuantitativa, ya que en la actualidad no hay una oferta de intermediación turística a nivel de agencias minoristas y mayoristas claramente posicionada en esta nueva modalidad turística.

En la mayoría de las ocasiones, existe una clara correlación entre el número de visitantes que reciben los enclaves dark y las acciones de marketing que se desarrollan, de manera que es 
una correlación que se retroalimenta. A continuación, se muestra en la Tabla 3 una serie de lugares dark más visitados del mundo en la actualidad y sus correspondientes ingresos brutos anuales en millones de euros. Los datos proceden de portal específico dark sites (http://www.dark-tourism.com) y de las páginas correspondientes a cada museo, enclave o recurso turístico dark. A simple vista y sin grandes cálculos, resulta sencillo determinar el rendimiento económico que mueve el turismo dark a nivel mundial. Resulta sintomático, por ejemplo, como de forma directa y en resultados brutos, únicamente el abono de la entrada turística al acceder a Auschwitz (60 zlotys, 13,2€), genera alrededor de 33,6 millones de euros cada año.

Tabla 3: Millones de visitantes/ingresos anuales por enclaves dark.

\begin{tabular}{|l|c|c|}
\hline \multicolumn{1}{|c|}{ Top 10 enclaves dark } & $\begin{array}{c}\text { Millones de } \\
\text { visitantes } \\
\text { anuales }\end{array}$ & $\begin{array}{c}\text { Ingresos brutos } \\
\text { anuales en } \\
\text { millones }\end{array}$ \\
\hline $\begin{array}{l}\text { 1- El museo nacional 11/S “Zona Cero" Nueva York, } \\
\text { EE.UU. }\end{array}$ & 5 & 50 \\
\hline 2- La ciudad antigua de Pompeya, Nápoles, Italia & 3,4 & 47,6 \\
\hline $\begin{array}{l}\text { 3- El cementerio nacional de Arlington, Washington D.C., } \\
\text { EE.UU. }\end{array}$ & 3 & Entrada libre \\
\hline $\begin{array}{l}\text { 4- El museo memorial de Auschwitz-Birkenau, Cracovia, } \\
\text { Polonia. }\end{array}$ & 2,3 & 33,6 \\
\hline $\begin{array}{l}\text { 5- La prisión de Alcatraz, San Francisco, EE.UU. } \\
\text { 6- El museo memorial de Pearl Harbour, Hawai, EE.UU. }\end{array}$ & 1,5 & $\begin{array}{c}\text { Entrada libre } \\
\text { incluido) }\end{array}$ \\
\hline $\begin{array}{l}\text { 7- El muro de Berlín, el museo Checkpoint Charlie..., } \\
\text { Berlín, Alemania. }\end{array}$ & 1,1 & 15,95 \\
\hline 8- Las catacumbas de París, Francia. & 0,8 & 11,2 \\
\hline 9- La casa de Ana Frank, Amsterdam, Holanda. & 1,2 & 15 \\
\hline 10- El museo memorial de la paz de Hiroshima, Japón. & 0,7 & 1 \\
\hline
\end{tabular}

Fuente: Portal específico Dark-Tourism y datos de webs oficiales [9/11 Memorial Museum (www.911memorial.org/), Alcatraz Island National Park Service (www.nps.gov/alca/index.htm), National Park Service, Pearl Harbor National Memorial (https://www.nps.gov/valr/index.htm), Pompeii Sites (http://pompeiisites.org/en/), Arlington National Cemetery (www.arlingtoncemetery.mil), Les catacombes de Paris (www.catacombes.paris.fr), Auschwitz-Birkenau (http://auschwitz.org/en/), Anne Frank Museum (www.annefrank.org/es/), Hiroshima Peace Memorial Museum (http://hpmmuseum.jp/?lang=eng) y Mauer Museum Haus Am Checkpoint Charlie (www.mauermuseum.de/en/start/)] 2020. Elaboración propia 
La era del hipermedia se ha convertido en una nueva estrategia de marketing y de captación de este segmento del mercado turístico para que el turismo dark gane en competitividad y pueda evolucionar y reconvertirse ante posibles adversidades y nuevas necesidades o transformaciones del mercado, afrontando nuevas técnicas comerciales de carácter circular para facilitar su orientación hacia un cliente prosumer ${ }^{7}$ (Kotler, Amstrong, 2008; Ayala, 2015). Está claro que no es casual el tono, las imágenes elegidas o la información mostrada, por cuanto más famoso es el enclave de turismo dark, más acciones de marketing específico se emplean para crear un escenario dark con posibilidades reales de estructuración y consolidación, aun cuando en muchas ocasiones se sustente en potentes y rigurosos contenidos históricos para evitar que el consumidor lo acepte como algo frívolo, banalizado o desvirtuado.

Desde luego, no siempre el marketing dark es aceptado como positivo o acorde con la realidad histórica y la autenticidad de los hechos y recursos territoriales que sirven de base a esta modalidad turística por parte de los organismos responsables de la promoción y comercialización de los destinos afectados. Existen, en este sentido, recursos dark que no son explotados turísticamente en algunos países que se avergüenzan en la práctica de tenerlos y en no pocos casos han sido determinados medios de comunicación más o menos amarillistas o sensacionalistas los que se han encargado de "venderlos" y utilizarlos lucrativamente mediante potentes campañas de marketing fomentando el fenómeno del necroturismo y, desde luego, no siempre utilizando criterios adecuados de veracidad, objetividad y autenticidad históricas. Por ejemplo, y en el caso de España, podemos hacer referencia a enclaves de episodios trágicos como "la matanza de Puerto Hurraco", "los crímenes de Alcàsser" o a nivel internacional el bosque de Aokigahara en Japón. Por otro lado, es verdad también que en algunos países como Estados Unidos se comercializan algunas rutas de los asesinos en serie como el tour de Charles Manson por todo Beverly Hills sin tan siquiera necesidad de justificar el producto con referentes históricos y culturales.

\section{Enfoques del turismo dark desde una óptica sostenible}

La sostenibilidad de los destinos turísticos se está convirtiendo poco a poco en un aspecto clave de la propia estrategia turística y en un nuevo indicador de su competitividad a nivel mundial. Con el turismo dark se pretende dar un nuevo uso a recursos endógenos infrautilizados o inexplotados al tiempo que diversificar la oferta turística minimizando el impacto cultural y natural de la sobreexplotación de algunos recursos vinculados a las tradicionales tipologías turísticas masivas y al propio monocultivo turístico dependiente de una determinada modalidad de turismo.

Igualmente, el turismo dark puede contribuir al despertar y emergencia del turismo y el desarrollo de economías locales de algunos destinos que, tradicionalmente, han sido eclipsados por el turismo de masas. Explotar dicha tipología turística es una oportunidad, en fin, para el fortalecimiento y la diversificación de las actividades económicas, sin perjuicio de asumir los nuevos retos de la industria turística en materia de responsabilidad general (Jafari, 1986; Rivera, 2012), rentabilizando una estrategia de sostenibilidad integral en los productos turísticos para generar un valor añadido de carácter preferentemente diferencial..

En diversas regiones de España, por ejemplo, como es el caso de Teruel, se produce lo

\footnotetext{
${ }^{7}$ No solamente consumen los servicios, sino que los crea, "produce" contenido, opiniones e información. En la era del hipermedia se ha convertido en una nueva estrategia de marketing y de captación de la demanda y además con esta fórmula se logra ganar competitividad, se permite que el negocio pueda evolucionar y reconvertirse ante posibles adversidades o situaciones de crisis o ante nuevas necesidades de mercado (Park, Sun-Woo, Chul-ho y Suk Choi, 2017).
} 
que Violier denomina como "círculos viciosos", argumentando que los destinos que son "pobres" lo son porque siempre lo fueron, pero que para dejar de serlo solo dependen de sí mismos (Guzmán y Fontela, 2003; Violier, 2008). Además, las actividades turísticas de dichas regiones no están plenamente desarrolladas y articuladas pese a las potencialidades y singularidades existentes para el turismo dark. En consecuencia, existe una carencia de medios económicos importantes, los niveles de ingresos son escasos y eso genera que se desincentive la inversión empresarial (Jurdao, 1992). Una de las ideas defendidas es, en este sentido, que con el desarrollo del turismo dark en dichas regiones se podría gestar un cambio, romper el círculo vicioso original que se comentaba y propiciar un estímulo para la inversión.

Claramente el desarrollo de un turismo dark en España es incipiente a la vez que peculiar en la actualidad. Por ello, se requiere de un modelo de análisis diferente y entender que las dependencias económicas para desarrollar los recursos endógenos infrautilizados son el principal lastre hacia una mayor prosperidad local. Por otro lado, las fugas económicas son una realidad y fomentan la teoría de los círculos viciosos de Violer que se comentaba anteriormente. Es necesario, en este sentido, integrar y dotar de relevancia a los proyectos turísticos locales relacionados con los recursos endógenos "durmientes" como el turismo dark, por encima de inversiones o proyectos foráneos. Las políticas de dinamización turística han estado amparadas en modelos llenos de obstáculos para las actividades empresariales locales y de iniciativa comunitaria e incluso no teniendo en cuenta los intereses de la población local y generando impactos irreversibles que hipotecan su calidad de vida. Si en el desarrollo del turismo dark no existe cierto control local, por ejemplo, mediante la salvaguarda de los recursos territoriales y las rutas temáticas bien planificadas mediante la colaboración público-privadas de las entidades locales u órganos de gestión de destinos, los proyectos están condenados al fracaso (De Oliveira, 2007; Rivera, 2016).

El monocultivo turístico en España tiene, en cierto modo, lo que podemos denominar como el "síndrome holandés", al atraer todas las inversiones hacia subsectores productivos que utilizan de forma intensiva los recursos disponibles en agravio del resto de actividades económicas. Y, como consecuencia de esta monofuncionalidad turística, existe una escasez de de recursos realmente disponibles para diversificar la economía (Ebrahim-zadeh, 2003). Si la explotación intensiva de estos recursos pierde competitividad o sufre síntomas de agotamiento, entonces la región puede padecer un proceso de decadencia al ser incapaz de restaurar la estructura productiva o atraer nuevas actividades (Corden y Neary, 1982).

En conclusión, esta tipología turística al ser incipiente tiene la ventaja de aprender de los errores de las políticas turísticas pasadas y, por ello, se debería de gestar desde sus raíces un modelo realmente sostenible, entendido éste como aquel que es sensible a la realidad social, económica y medio ambiental del entorno y que colabora con programas destinados a satisfacer las necesidades de la comunidad. En definitiva, un modelo sostenible que establezca estrategias que contribuyan a optimizar los recursos y crear empleos verdes que ayuden a preservar el medio ambiente a través del abandono de sectores más tradicionales y promover otros más emergentes como las energías renovables y la eficiencia energética. El reto del modelo sostenible es lograr un equilibrio entre ofrecer productos/servicios socialmente beneficiosos, ambientalmente responsables y por supuesto económicamente viables (Stock, 2003; Rivera, 2013).

Según algunos autores como Weaver o Stöhr, para hablar de desarrollo local, al menos en la teoría, se tienen que manifestar tres dimensiones: un carácter territorial, integral y comunitario, ser llevado a pequeña escala en base a las necesidades de la población y, por último, se debe sostener fundamentalmente con recursos endógenos (Vázquez, 1988). Y la política turística sostenible se debe dirigir a la creación de productos turísticos específicos y 
competitivos que mejoren la oferta tanto de alojamiento como de restauración, recreación e intermediación turística, hacia la participación e implicación ciudadana, la colaboración público-privada e interempresarial y la coordinación local y provincial (García, 2010).

Finalmente, un proyecto de turismo dark bajo el paraguas de una política turística sostenible podría mitigar el éxodo rural y la despoblación, la marcada estacionalidad, los niveles de ocupación y facilitar la rehabilitación del patrimonio histórico y cultural y una mejor calidad y oportunidades en el empleo. En definitiva, el turismo dark como recurso endógeno aún incipiente pero sui generis y diferencial en muchos casos, puede, en fin, ser el salvavidas que logre minimizar los efectos de las crisis periódicas del sector turístico y facilitar la recuperación de los destinos afectados (Pérez de las Heras, 2004), ya que también conforma un tipo de oferta muy adaptada y sugerente para el turismo de proximidad y nacional en períodos de crisis de la demanda de origen extranjero como la que vivimos.

\section{Enfoques del turismo dark desde una óptica ética y jurídica}

Es un tema tremendamente complejo debido a la herencia histórica con la que cuenta nuestro país, una guerra civil, cuarenta años de dictadura y aún muchos conflictos políticos derivados del sufrimiento que han quedado pendientes y sin resolver. Sin embargo, resulta necesario hacer un ejercicio que sea capaz de ofrecer unas pinceladas de argumentos jurídicos y éticos que puedan sustentar el fomento de la práctica del turismo dark en España, como ya se da en otros países del Mundo. Por un lado, se puede interpretar que cualquier actividad que atente a la dignidad del ser humano, que trivialice, banalice o exalte determinados comportamientos que producen profundo dolor ajeno (y valiéndose del morbo o la atracción de los mismos) debieran establecer un límite claro a la autonomía de la voluntad privada, por lo que debería estar regulada por el derecho. Igualmente, también es posible pensar que el derecho tiene una dimensión ético-pública y que la comercialización de los bienes y servicios que vulneran la dignidad humana resulta, por lo tanto, susceptible de moderación y limitación desde un punto de vista jurídico.

Por otro lado, en una consulta realizada al catedrático de derecho mercantil Aitor Zurimendi Isla, de la Universidad del País Vasco, nos aclara que para poner en marcha este tipo de actividades turísticas (por ejemplo, rutas dark o cursos destinados a especialistas) en el espacio público, basta por lo general con pedir una autorización a la administración correspondiente, las Comunidades Autónomas o los Ayuntamientos. No habría que cumplir con otros requisitos especiales o adicionales, sino los de carácter general y los propios del tipo de actividad. Complementariamente, la regulación europea también exige que estos requisitos administrativos sean respetuosos con la libertad de empresa, porque constituyen un obstáculo, limitación o barrera de entrada para el ejercicio de una actividad empresarial.

Los requisitos administrativos deben ser siempre proporcionados a la consecución de un interés público y no se podrá negar una autorización de forma arbitraria. Es decir, las administraciones no pueden argumentar problemas éticos (no es ningún requisito) y en el caso de que alguna administración denegase la autorización para desarrollar dichas actividades, lo debería de justificar de forma objetiva e, incluso, sería fácilmente recurrible, porque se tiene que comprobar que los requisitos vigentes se cumplen o no y argumentar el por qué se deniega.

Objetivamente tan sólo se podría negar la autorización en el supuesto de que no se cumpliera con los requisitos establecidos que garantizan que se protejan los intereses públicos. En el caso de las rutas dark, si se ofrecen datos públicos y reales, sin incurrir en vejaciones, falsedades o datos que denigren a las posibles víctimas, nadie tiene argumentos jurídicos para obstaculizar el desarrollo de la actividad, ni tan siquiera los familiares, porque es cierto y es 
público y no se incurre en ninguna actividad ilícita. Zurimendi afirma, en este sentido, que "no es ilícito contar cosas reales que han pasado y que son ciertas".

Sin embargo, en determinadas rutas como en un cementerio, quizás las administraciones puedan restringir o impedir las visitas puesto que es un lugar con un tratamiento especial donde se velan a los muertos. En este caso, sería lógico que se denegara o restringiera la actividad, puesto que prevalece la defensa del interés colectivo. Y respecto a las rutas relacionadas con asesinatos en lugares públicos, las administraciones no pueden denegar la autorización, sino que se aplica igualmente la normativa vigente como para cualquier otra ruta y la administración no debe enrocarse en fundamentos éticos para no autorizarlas.

En conclusión, la denegación ocurre únicamente si se argumenta que no se cumple el interés público (control ex ante $e^{8}$ ) o que no se cumple el requisito vigente y establecido a priori y en una checklist. Asimismo, también existe el control ex post, es decir, si las administraciones deniegan la autorización, deben de justificar qué requisitos del listado de la norma no se cumple y razonarlo. Zurimendi señala, en este caso, que "no pueden existir cuestionamientos éticos, ni subjetividad, ni arbitrariedad".

Otras fuentes jurídicas consultadas estiman que también hay que ponderar el matiz de "atentar a la dignidad del ser humano", ya que resulta bastante discutible demostrar que ciertas actividades turísticas dark estén consideradas como un atentado o que banalizan ciertos comportamientos antisociales o inmorales. Por ejemplo, el campo de concentración de Auschwitz, la denominada Zona Cero o Chernóbil son claros ejemplos de turismo dark que se comercializan ampliamente y que se sostienen con argumentos históricos, académicos o conmemorativos, sin llegar a considerarse, en ningún caso, lugares que vulneran la dignidad humana.

El concepto ético o no ético es bastante discutible, en definitiva, al estar sujeto a múltiples interpretaciones que pueden condicionar el planteamiento y el desarrollo de esta actividad turística. Finalmente, el tratamiento que se haga del turismo dark también difiere según las casuísticas tan diferentes que pueden darse. Por ejemplo, comercializar un curso para especialistas o futuros criminólogos que quieren recrear asesinatos sin resolver o ya resueltos in situ no sería mercantilizar un suceso y un enclave dark, ya que está más que argumentado y, en consecuencia, no se cuestionaría el componente ético.

\section{Resultados y confirmación de las hipótesis en España}

Para la hipótesis I, sobre si "existen recursos dark en España, aunque el turismo dark no sea fácilmente extrapolable a las características generales del mercado turístico español", se extrajeron y tabularon los datos de las primeras preguntas de la muestra heterogénea de los cien encuestados, arrojándose los siguientes resultados: el 85,6\% considera que el turismo dark es un producto turístico viable y con potencialidades de futuro; el 75,6\% se considera consumidor directo de productos turísticos dark; $e$ l 69,7\% advierte que existen en la actualidad productos turísticos dark en España bien identificables y, en concreto, el 66,3\% de los encuestados se imagina alguna posible y nueva creación de productos dark.

Aunque no existen estudios de referencia específicos sobre los recursos territoriales de turismo dark en el mercado turístico español, sí se puede afirmar que existen recursos suficientes y variados para el desarrollo de este segmento de demanda. En tal sentido, emos elaborado para este estudio una recopilación con los enclaves nacionales e internacionales más

\footnotetext{
${ }^{8}$ El empleo de las autorizaciones es el modo clásico de la intervención administrativa en el que se comprueba ex ante, si una determinada actividad respeta o se adapta a los intereses colectivos.
} 
conocidos (Anexo 1). Y, complementariamente, con las entrevistas realizadas a investigadores, profesores o profesionales del sector turístico y conocedores de la materia, se han podido extraer opiniones que ayudan a reafirmar esta tesis y contestar positivamente a la hipótesis I. Entre ellas, hemos de destacar las respuestas de los siguientes encuestados:

Lola Rubio, CEO de la Agencia de Viajes Sevilla4Real: "Sí, existen suficientes recursos dark [...] y el turismo dark es un producto más de la oferta variada que tiene nuestro país, es perfectamente factible como producto turístico en España y compatible con otras muchas tipologías".

Julián Rey, escritor: "Los adjetivos son muy importantes, si hablamos de producto como mercancía sí, si hablamos de factibilidad como posible producto para España sí, totalmente lo creo [siempre que se resuelvan otras incógnitas y barreras...]. Sin embargo, si pensamos en la rentabilidad del turismo dark, tengo dudas importantes".

Daniel Liviano, profesor de la UOC: "No es que pueda ser factible, es que ya lo es y no nos hemos dado cuenta" [...] "por ejemplo la Semana Santa se puede considerar turismo dark porque es una representación teatralizada basada en el sufrimiento y la muerte de un personaje religioso e histórico muy popular a lo largo y ancho de la geografía española".

Con estos primeros datos de análisis cuantitativo y cualitativo, se desprende que la muestra reconoce en su mayoría que el turismo dark tiene una clara naturaleza de producto turístico y, por añadidura, se considera que existen productos turísticos dark en España. Con el adjetivo extrapolable, y según la propia definición de la RAE, queremos hacer referencia a la aplicación a un ámbito territorial concreto y en nuestro caso a España. En la encuesta realizada un 66,3\% se imagina perfectamente la comercialización de rutas del turismo dark en España se pusieron de ejemplo las rutas de asesinos en serie como en Estados Unidos- pero llamativamente solo el 38,2\% las consumiría, y razonan su respuesta en una pregunta abierta donde destacan respuestas como: "En USA me parece lo normal porque no tienen historia y pueden vender lo que consideren, pero creo que en España tenemos miles de lugares impresionantes, tanto naturales como culturales, como para tener que visitar el lugar donde alguien asesinó a otra persona". Otra de las respuestas advierte de conflictos de intereses: "puede ser entretenido, y me gustaría, pero no me imagino un tour en España asî".

En la encuesta se elaboró, asimismo, una pregunta muy concreta que buscaba aclarar la hipótesis y es la siguiente: "En Estados Unidos o en el Reino Unido el turismo dark es más popular que en España. ¿Por qué cree que es así? Marque todos los motivos que considere". Se configuro con un modelo de respuesta múltiple y con la opción de "otros" y los resultados han fueron ciertamente interesantes. En concreto, el 38\% de los encuestados consideraron que existe un bloqueo cultural a la hora de diseñar productos dark en España; el 27\% pensó que hay bloqueos de tipo religioso para la popularización del turismo dark en nuestro país, mientras que el 28,4\% considera que existen bloqueos de carácter ético y otro 6,3\% piensa que hay bloqueos legales. En la respuesta "Otros", por su parte, destacan los que manifiestan que "no hay marketing adecuado y suficiente" y que "tenemos otros muchos recursos turísticos y no sentimos esa necesidad o atractivo del turismo dark".

Uno de los problemas en la investigación del turismo dark es la "extrapolaridad", o sea, la dificultad, por un lado, de catalogar y discernir sobre lo que realmente puede asociarse al turismo dark. Por ejemplo, una visita a un campo de concentración puede tener una motivación educativa y, en consecuencia, cultural, espiritual y de interés histórico, pero no tiene por qué ser un producto propiamente dicho de turismo dark aunque implique la visita a un lugar de carácter luctuoso. Quizás, por ello, existen diversas interpretaciones un tanto contradictorias sobre lo que se entiende por turismo oscuro. Y así, mientras que Jamal y Lelo (2011) afirman que es una construcción social más que un hecho objetivo, para Stone y Sharpley (2008), 
aunque determinados enclaves turísticos o atracciones relacionadas con la muerte se presenten y comercialicen bajo un prisma educativo, de entretenimiento o de recuerdo histórico, en realidad lo que subyace y atrae a las personas en su visita es esa sed ávida y morbosa de "consumir" la muerte como si fuese una mercancía.

Otros estudios de referencia también comentan que la extrapolaridad está condicionada por múltiples factores. Por ejemplo, la heterogeneidad del fenómeno es un terreno muy inexplorado en lo que se refiere a las motivaciones, de manera que mientras muchos tienen una motivación de satisfacer la sed por lo "macabro", incluso la "alegría por el sufrimiento ajeno" o acudir a un lugar para cerciorarse de qué personas sufrieron allí o recibieron "aquello que se merecían", para otros "puede llegar a tener una motivación moral o espiritual, cuando se busca visitar el escenario de una tragedia o un genocidio para mostrar empatía con las víctimas, recordarlas y honrarles" (Liviano, 2019).

Tampoco parece fácil realizar extrapolaciones a España sobre turismo dark al carecerse de estudios comparativas sobre legislación aplicable a esta modalidad turística en diferenes países y su incidencia en el desarrollo de productos turísticos asociados. Lo cierto es que mientras que en Estados Unidos se agotan las entradas para realizar la ruta Helter Sketer, aquélla que recorre por todo Bervely Hills los enclaves de los crímenes de Charles Manson y de sus fanáticos, o en México se ponen de moda los denominadas "narco-tours" de Medellín y Pablo Escobar, en España resultaría insólito, moralmente reprochable y legalmente más complejo, comercializar la ruta de "Las niñas de Alcácer" o "Los asesinatos de Puerto Hurraco", por ejemplo. Por lo tanto, el marco geográfico, la "sensibilidad", la legislación aplicable y los condicionamientos socio-culturales son también factores muy condicionantes en el desarrollo de productos dark en nuestro país.

Algunas respuestas concretas al planteamiento de esta hipótesis que hemos encontrado en las encuestas son ciertamente sugerentes:

Julián Rey, escritor, considera que "aunque tengamos recursos dark interesantes (quizás no tan famosos a nivel internacional) que fomenten un turismo dark, al menos interno y nacional, la realidad turística española no acaba de replicar el modelo que sí funciona en otros países como Estados Unidos o el Reino Unido".

Daniel Viera, guía de viajes, señala que "España ya vende otra cosa que le renta mucho más y tiende a especializarse, ya que es más sencillo vender lo que sabes que se vende bien que no reinventarse".

Para Lola Rubio, CEO de la Agencia de Viajes Sevilla4Real, "Nuestros productos de turismo negro tienen éxito, se venden bien, pero son lo que más esfuerzos implican y se tienen que justificar muy bien desde el punto de vista histórico y cultural. Por ejemplo: una ruta por la naturaleza no implica tanto trabajo ni de justificación ni de marketing, ya quese entiende perfectamente" [...] "Lo que quiero decir, es que para vender algo sobre el turismo negro hay que trabajar el doble y no siempre compensa desde el punto de vista económico".

Se puede llegar a la conclusión que los resultados obtenidos en los diferentes tests de verificación son bastante coincidentes y complementarios, de manera que podemos afirmar que el turismo dark no es fácilmente extrapolable a España o a la cultura española. Por tanto, la hipótesis I queda verificada.

La segunda hipótesis sobre si "En España el turismo dark no ha superado los prejuicios y la barrera de lo políticamente incorrecto y si no hay un componente histórico-cultural claro en el turismo dark, siempre se estigmatiza su consumo", a priori resulta bastante compleja de discernir. El 46,7\% considera que los consumidores de productos dark no tienen unas "patologías concretas", sino intereses diferentes, simplemente. El 63,3\% de los encuestados 
piensa que se estigmatiza el consumo de productos dark en función del grado de intensidad, mientras que el 28,9\% sostiene que, dependiendo del grado de intensidad, el consumo del turismo dark sí puede encerrar algún tipo de patología del público demandante. Por otra parte, el 34\% se declara abiertamente consumidor de productos dark, si bien muchos encuestados no se declararon consumidores dark porque su concepto dark era muy reducido o confuso, lo reinterpretaban o incluso algunos lo relacionaban con productos únicamente de temática y estética de vampiros.

El 34,2\% afirma que aquello aceptado como frívolo o cultural en los productos dark también es muy subjetivo. Resulta sintomático de nuevo los datos de las primeras preguntas de la encuesta, ya que el 69,7\% piensa que hay productos dark en nuestro país, pero, curiosamente, ese mismo porcentaje no se considera consumidor de productos dark. Aparentemente, resultan datos contradictorios, pero ayudan a establecer indicios de estigmatización en el consumo. Es llamativa, asimismo, la idea obtenida de la pregunta "Visualice un campo de concentración como el de Auschwitz, ¿piensa que el desapego temporal a un escenario dark fomenta su consumo?". En concreto, algunos encuestados no consideraban que un campo de concentración sea un enclave dark porque tiene un componente histórico-cultural. Y, por último, el 62,3\% cree que el componente histórico o cultural de los productos no solo es una manera de evitar la estigmatización, sino que además es un complemento del reclamo turístico. Es decir, el 62,3\% piensa que se justifica mejor su consumo si se combina con otros intereses.

Resulta imprescindible para comprender el posible estigma al turista dark hablar del debate ético y moral en el consumo del turismo dark. ¿Dónde está el límite de lo ético y lo moral en el turismo dark?. En primer lugar, una interpretación errónea del producto del turismo dark acarrea una ausencia total de autenticidad y, por eso, las recreaciones frívolas, subjetivas, irreales, exageradas, sesgadas, condicionadas a una ideología o falsas, fomentan el estereotipo de que el turista dark busca algo oscuro, y lo oscuro está, comúnmente, asociado a algo malo, negativo y socialmente inaceptable (Stone y Sharpley, 2009). Según Stone, la ausencia de componentes culturales o de rigor histórico, es rápidamente captada por el visitante: cuando no la encuentra lo cataloga como dark, cuando es capaz de verla lo tipifica como historia. Es decir, lo justifica y no se crea el estigma. Por lo tanto, la escisión que a priori realiza el visitante es la clave.

En segundo lugar, la conducta reprochable de algunos visitantes en determinados enclaves dark como los campos de concentración o los museos de genocidios ha perpetuado un cliché de los mismos muy negativo que ha provocado que hasta las autoridades locales hayan tenido que intervenir y colocar avisos y carteles para que mantengan una actitud respetuosa y un código ético de comportamiento. Esta conducta retroalimenta y generaliza a los turistas dark, estigmatizándolos con carácter general. El ejemplo más impactante lo podríamos encontrar en el campo de concentración de Auschwitz, donde medios nacionales e internacionales se hicieron eco de la insensibilidad de los visitantes que se hacían selfies sonrientes y con muecas irrespetuosas en los hornos crematorios para subirlas a las redes sociales. Aunque serían dos razones argumentadas para estigmatizar al turista dark, la realidad es que dichas prácticas reprobables son propias de turistas dark fortuitos, es decir, aquellos que visitan el lugar porque forma parte del itinerario turístico o de la lista must visit, y no porque tengan algún tipo de interés específico respecto al mismo. El turismo dark también implica cierto conocimiento del lugar a visitar y, en consecuencia, el respeto y concienciación hacia sus contenidos ya es intrínseco.

En la encuesta y en la entrevista realizada se infiere que no todos interpretan o entienden bien el turismo dark. Para muchos, existe un sentimiento malsano, asociado a prácticas que podrían definirse como voyerismo. Con el turismo dark siempre se reaviva, además, el debate 
de si la promoción y el fomento a este tipo de atracciones es una decisión ética. Por un lado, muchas personas consideran que el turismo dark implica una violación de derechos de quienes han fallecido o sufrido, así como los de sus descendientes. No obstante, la línea de lo políticamente aceptable, moral y ético nunca ha estado clara en ninguna práctica. Es cierto que en algunos casos existe una aceptación, sin cuestionamientos, por parte de la sociedad, mientras que en otros se produce un rechazo draconiano y pleno. Por ejemplo, se acepta perfectamente la visita, sin estigmas, a los cementerios como el de Père Lachaise en París o a las ruinas de un pueblo destruido por la Guerra Civil española como el de Belchite en Zaragoza o al enclave de la tragedia de Pompeya.

En los casos anteriores, se aprecia que el elemento histórico-cultural es el eje que marca la línea divisoria entre lo aceptable y lo no aceptable. Si eliminamos el condicionante cultural en la ecuación, el turismo dark se estigmatiza fácilmente cuando surgen a la luz casos como el constante aumento de visitas a lugares como Praia da Luz, motivados por la trágica desaparición de Madeleine McCann, o la casa donde permaneció secuestrada la austriaca Natascha Kampusch, que hasta se vio moralmente obligada a comprar la propiedad para evitar que fuera un destino visitado por turistas que recreaban el encierro.

Otro tema importante es el marco temporal y la diversión. Parece evidente que la frivolidad no solamente es un tema de valores culturales, sino también temporales. Cuánto más lejano en el tiempo sea mayor la frivolización parece existir. Stone pone el ejemplo en el "London Dungeon" donde, como atracción londinense de primer orden, se representan explícitamente las torturas y la muerte. En consecuencia, se convierte en un lugar donde los visitantes se entretienen al estilo "baudrillardiano" a través de actos simulados de asesinatos, incluyendo ahorcamientos y cortes de gargantas (Stone, 2009). Por lo tanto, el otro gran condicionante del estigma es el componente temporal, o sea, que cuanto más alejado en el tiempo esté el suceso dark, menos estigma existe.

Adicionalmente, para esta hipótesis se han utilizado los comentarios extraídos de las entrevistas. Lola Rubio, CEO de la Agencia de Viajes Sevilla4Real, comenta que "Es posible, todo depende de cómo se vendan y de cómo estén construidas estas rutas" [...] "si no hay un componente cultural que lo sostenga, su consumo está más limitado". La entrevistada hace referencia a los tours por la ciudad de Sevilla que su empresa realiza (Sevilla Macabra).

Daniel Viera, guía de viajes, opina que "El turismo dark es un tema tabú, se tiene que justificar muy bien para que no tachen a los productos o a los consumidores de frívolos".

Julián Rey, escritor de viajes, afirma sobre pregunta "¿todos los visitantes de Auschwitz tienen inquietudes históricas y culturales en fotografiar los hornos crematorios?, que no todos las tienen, ni mucho menos, ya que la sociedad estigmatiza a sus consumidores porque aún no están socialmente aceptados y este turismo no se considera políticamente correcto. En Estados Unidos -señala- "he podido observar otra realidad, la mercantilización es predominante y te das cuenta de que lo frívolo es relativo y puramente cultural". "El estigma existe porque está mal visto y es un tema tabú en nuestro país [...] hemos pasado 40 años de dictadura y las heridas entre la Guerra Civil no se han cerrado, muchos quieren olvidarse del tema" [...] y "otros, algunos, únicamente, quizás los más sinceros o valientes, están dispuestos a admitir que visitan los lugares oscuros sin motivación histórica”.

Finalmente, es muy interesante la aportación de Daniel García, tanatopractor ${ }^{9}$ y turista dark, que piensa que "el estigma se genera, en parte, por la interpretación a la muerte. Es cierto

\footnotetext{
${ }^{9}$ La Tanatopraxia hace referencia al conjunto de prácticas que se efectúan sobre un cadáver desarrollando y aplicando métodos destinados a su higienización, conservación, embalsamamiento, restauración, reconstrucción y cuidado estético del cadáver.
} 
que, en cualquier lugar, el tema de la muerte se entiende de forma más natural y aquí hasta hace pocos años era un tema muy tabú, ahora se está naturalizando muy lentamente". Occidente respecto a Oriente es extremadamente visceral y menos natural. En España al menos es así. [...] Aún seguimos tratando la muerte de manera muy visceral (la muerte la vemos como un tema muy oscuro que se debe evitar por miedo). Daniel García aporta un elemento nuevo para entender el estigma, el componente generación. "El estigma es mayor o existe por parte de gente que pasa de los 35 o 40 años hacía arriba, es una generación que hemos vivido la muerte de otra manera, mientras que ahora las nuevas generaciones saben de todo y se han informado mucho más gracias a internet, y tienen mucha más curiosidad al respecto".

Daniel García añade también su opinión respecto a los condicionantes del marco temporal para el desarrollo del turismo dark. Señala, en concreto, que "es muy difícil el comercializar un tema como el de las niñas de Alcàsser, aunque han pasado muchos años, nosotros lo tenemos muy reciente todavía, a mí personalmente me dejó muy marcado (me parecería cruel), y en todo caso se podría empezar a hacer turismo dark con hechos de principios de siglo XX o anteriores, que serían más receptivos para la gente y desde ahí poco a poco ir avanzando".

En definitiva, sobre esta hipótesis ciertamente compleja, se ha podido contrastar que los componente cultural, histórico, temporal y generacional son condicionantes para estigmatizar el turismo dark. Por consiguiente, y a raíz de la amplia argumentación anterior, queda probado que se cumple la antedicha hipótesis. Finalmente es interesante el planteamiento del futuro del turismo dark que ofrece Daniel García al afirmar que "me imagino perfectamente una explosión del turismo dark en los próximos años. Por ejemplo, en mi profesión de tanatopractor cada vez hay mayor interés por parte de las personas jóvenes. Pienso que tienen menos prejuicios, más información, poseen nuevos planteamientos, conocen otras culturas... Por lo tanto, noto que la cultura está evolucionando y creo que el turismo dark formará parte de una nueva tipología de turismo bastante respetada y común como cualquier otra en la próxima generación”.

\section{Discusión}

La confusión durante años respecto al término turismo dark en la literatura científica no ha permitido grandes estudios en profundidad hasta hace relativamente poco tiempo. Este hecho quedó reflejado en la encuesta realizada. Uno de los problemas en la investigación del turismo dark, común a todos los investigadores durante las últimas décadas, ha sido la complejidad de catalogar e identificar qué pertenece exactamente al turismo dark. Por ejemplo: ¿Una visita a un campo de concentración es turismo dark o es turismo cultural o ambos?

Esta investigación respalda la tesis de Stone al considerar que los elementos vertebradores son siempre turismo y muerte, así como la de otros autores como Dunkley que identifican diferentes tipologías turísticas como partes del mismo tronco común del propio turismo dark. Aunque se ha recogido el estudio y el legado de Stone referente al espectro dark, en concreto en un artículo de la Universidad de Lancashire Central titulado "A Dark Tourism Spectrum: Towards a typology of death and macabre related tourist sites, attractions and exhibitions", se ha ampliado, reformulado y ejemplificado adecuadamente dicho espectro. Se ha diseñado una herramienta con una escala de grises, denominada darkmeter, con nuevas categorías, categorías secundarias y subcategorías para simplificar el totum revolutum semántico y estar en armonía con las necesidades actuales de entender mejor las implicaciones y casuísticas ciertamente diversas de dicha modalidad turística.

La encuesta y las entrevistas realizadas también han servido para corroborar el caleidoscopio de motivaciones de los turistas dark que señalaban los estudios de los principales autores. Por ejemplo, el concepto de la autocomprensión, la búsqueda de la propia identidad y 
el interés por el sufrimiento de Hartmann y Ashworth o la liberación de la adrenalina y la hiperexcitación de Crompton. A través de la encuesta y de las entrevistas se ha podido robustecer fácilmente las tesis desarrolladas por Stone, por ejemplo, cuando existe una ausencia de componentes culturales o de rigor histórico en el tratamiento de los recursos dark, se confirma que se crea el estigma de los consumidores dark.

La escasez de estudios de referencia específicos sobre los recursos dark del mercado español ha sido uno de los principales escollos en la investigación, aunque también una clara oportunidad de colocar la primera piedra angular sobre el turismo dark en nuestro país.

Respecto a las líneas de investigación para un futuro, resultaría interesante perfilar un posible proyecto nacional de rutas dark por España a partir de rutas preexistentes como el Camino de Santiago o la Ruta de la Plata, y desarrollar más las posibilidades reales de un producto dark a partir de propuestas de expertos y profesionales especializados en diferentes facetas de su estructuración y diseño (abogados, detectives, criminólogos o interesados en conocer in situ todos los detalles de una tragedia o de un asesinato). Igualmente, se ha visto la necesidad de entablar un plan piloto sobre recursos dark en la España vaciada como estrategia de transformación y desarrollo territorial y búsqueda de nuevas iniciativas de empleo.

\section{Conclusiones}

En este trabajo de investigación de temática innovadora y hasta controvertida, se han recopilado aportaciones de decenas de autores que, durante décadas, han ido dejando su impronta en temas relacionados directamente con el turismo dark y las nuevas tendencias del turismo experiencial. El poder vivir experiencias personalizadas, auténticas, diferenciales, genuinas, sensoriales, sui generis o a la carta en un entorno seguro es una motivación cada vez más extendida y será ésta, sin duda, todo un catalizador de nuevas transformaciones de la industria turística, incluida la española, sirviendo, asimismo, de oportunidad para el enriquecimiento de la oferta turística de algunos destinos maduros y en crisis.

Por lo que se refiere a los orígenes, el turismo dark siempre ha existido de alguna manera, aunque la consciencia sobre el mismo no fuera entendida como tal o no se haya mercantilizado propiamente. El turismo dark existe desde hace siglos y es una parte integrante de la historia y una herramienta para naturalizar y comprender la muerte. Para ello, se retrotrae hasta la Antigüedad donde se fundamenta el interés y la atracción por el turismo dark en las peregrinaciones y la muerte de individuos de importancia religiosa y mística. Específicamente, el primer ejemplo "moderno" de turismo dark lo encontramos en la Inglaterra del siglo XVII, donde se organizaban encuentros para presenciar las ejecuciones públicas o en la Francia del siglo XIX donde se vulgarizaron las visitas a las morgues en París o las escapadas para presenciar las muertes por guillotina. El turismo dark ha estado desde siempre vinculado a eventos históricos, la tragedia y la muerte.

Se ha puesto en evidencia que las clasificaciones clásicas y más básicas de los autores que trataron el tema hace una década, no han evolucionado a la misma velocidad que el fenómeno dark y, por lo tanto, no se han sabido explicar e identificar suficientemente los diferentes matices de su "escala de grises". Por esa razón, ha sido necesario gestar y alumbrar en este trabajo nuevas herramientas, como el espectro dark, el darkmeter, capaces de estar en armonía con las necesidades actuales de entender e interpretar mejor la casuística que implica el fenómeno estudiado.

El carácter motivacional del turismo dark también ha sido objeto de amplio análisis en en esta investigación y se ha podido llegar a la conclusión de que las motivaciones dependen del conocimiento, de la educación, de los vínculos e interrelaciones, de los gustos, de la 
intensidad y la escala de importancia y prioridades que tengan presentes los turistas. En consecuencia, se infiere que la motivación del turista dark es múltiple y no necesariamente única ni contradictoria, puede existir un conjunto de motivaciones que retroalimenten el interés en la práctica del turismo dark. Entre ellas se destacan motivaciones como los intereses históricos, los intereses culturales, el placer de la desgracia schadenfreude, el interés por lo insólito y lo inusual, el puro entretenimiento, el interés por rendir honores, el interés personal directo o indirecto.

Se ha evidenciado ampliamente, con más de un centenar de ejemplos concretos, que existen recursos dark suficientes en el mundo para que se desarrolle de forma arrolladora dicha industria, como también en España. Por añadidura, algunas cifras manejadas han sido bastante esclarecedoras, de manera que el turismo dark genera un volumen de visitantes importante, que se traduce directamente en pingües beneficios para los países que han sabido mercantilizarlo. En concreto, en España existen grandes recursos dark por explotar, pero hasta ahora se ha seguido perpetuando, sin grandes alternativas, un monocultivo turístico tradicional de sol y playa o genérico de turismo rural y de naturaleza o cultural en los que no se ha sabido encajar aún las nuevas tendencias de turismo experiencial entre las que hemos de incluir a la modalidad del turismo oscuro. Pese a todo, el turismo dark puede ser un catalizador de cambios capaz de dar viabilidad y aprovechamiento a recursos endógenos infrautilizados o en desuso en tiempos volátiles y de crisis de la industria turística española, necesitada de nuevas aportaciones innovadoras y de la diversificación de sus productos y ofertas. Existe, en fin, materia prima para desarrollar turismo dark en España, ya que existe un nicho de mercado emergente.

Por un lado, el futuro de la industria turística española pasa, entre otras cosas, por innovar en el mercado y ofrecer viajes "experienciales" y genuinos mediante el diseño artesanal de viajes para grupos reducidos de turistas o turismo individual que buscan "algo diferente". La idea será trabajar experiencias únicas, en este caso dark, con una mayor integración en los entornos y despojarse del patrón de turismo masivo de viajes de grupo que mantienen la cadena sempiterna de "autobús-foto-autobús". Por otro lado, el futuro de la dinamización turística pasa por entender cómo la industria española interpreta el mercado para aprovechar las ventajas competitivas de nuevos segmentos como el turismo oscuro.

En España, la difusión de las prácticas del necroturismo ha sido alentada tan sólo muy recientemente por los medios de comunicación y los reportajes, más o menos amarillistas, que han proliferado en los últimos años. En cambio, en otros países con mayor cultura dark, se han aprovechado de la era del hipermedia y la hiperconectividad para crear una nueva estrategia de marketing y de captación de un nuevo segmento de demanda cuantitativamente nada desdeñable en términos absolutos. Han ganado para ello márgenes importantes de competitividad y están permitiendo que el negocio dark pueda evolucionar y reconvertirse ante posibles adversidades, nuevas necesidades de mercado o afrontar mejor los nuevos comportamientos cambiantes de la demanda y las estrategias comerciales. Por ejemplo, el marketing dark ya no solo transmite la información de forma lineal, sino también circular, para generar, así, una conversión hacia un cliente prosumer.

Se ha trabajado también en este estudio sobre las dimensiones de la sostenibilidad y se ha llegado a la conclusión de que el turismo dark, como potencialidad territorial, lograría ciertos efectos beneficiosos para contribuir a la minimización del éxodo rural, la despoblación y la marcada estacionalidad de algunos destinos turísticos, mejorando los niveles de ocupación, la rehabilitación del patrimonio histórico y cultural, la calidad de empleo y las iniciativas de emprendimiento.

Las hipótesis, que se encuentran concatenadas, han quedado ampliamente verificadas y, para este estudio, se ha podido demostrar, después del análisis y la tabulación de los datos, que 
en España existen recursos potenciales para el desarrollo del turismo dark. No obstante, también se confirmó que no es fácilmente extrapolable el desarrollo de este tipo de turismo en otros países pioneros al mercado turístico español, al menos por ahora, ya que no existe como mínimo un componente histórico-cultural (además del marco temporal y generacional) suficientemente potente y reconocido para que se evite estigmatizar el consumo y la comercialización de los productos dark.

Con el turismo dark siempre se reactiva el debate de si la promoción y el fomento a este tipo de atracciones es una decisión ética. La línea divisoria de lo políticamente aceptable, moral y ético nunca ha estado clara en ninguna práctica y resulta obvio que en algunos casos existe una aceptación, sin cuestionamientos, por parte de la sociedad, mientras que en otros se produce un rechazo draconiano y total. Por ejemplo, se acepta perfectamente la visita, sin estigmas, a los cementerios como el de Père Lachaise en París o a la tragedia de Pompeya.

Desde el punto de vista jurídico, las administraciones públicas no pueden denegar la autorización para desarrollar productos turísticos dark por cuestionamientos meramente éticos, subjetivos o arbitrarios. La denegación únicamente estaría motivada si se argumenta que no se cumple el interés público (control ex ante) o que no se cumple el requisito vigente y establecido a priori y en una checklist. Tampoco el matiz de interpretar que los productos turísticos dark implican "atentar a la intimidad del ser humano" resulta un motivo de bloqueo. El campo de concentración de Auschwitz, la Zona Cero de Nueva York o Chernóbil son claros ejemplos de turismo dark que se comercializan y que se sostienen con argumentos históricos, académicos o conmemorativos, sin llegar a considerarse, en ningún caso, lugares que vulneran la dignidad humana.

En los casos anteriores se percibe que el elemento histórico-cultural es el eje que marca la línea divisoria entre lo aceptable y lo inaceptable y en cuanto al marco temporal y el atractivo recreativo, se ha podido comprobar cómo cuanto más lejano en el tiempo sea el evento o escenario utilizado es mayor el nivel de banalización o frivolización, según los casos, pero menos estigma existe sobre los turistas que gustan de su visita y conocimiento. Finalmente, también se ha podido interpretar que el estigma es generacional. Las generaciones de los niños de la postguerra (Silent Generation 1930-1948) y la generación del Baby Boom (1949-1968) han estigmatizado más el turismo dark que las generaciones X (1969-1980), Millennials (19811993) y Z (1994-2010). Éstas últimas, gracias a la hiperconectividad y a la cultura de nativos digitales, entienden y sienten de manera más normalizada el turismo dark como una tipología turística curiosa y de cierta atractividad, sin estigmatizarla, pero advierten de que vive aún rodeada de tabúes.

\section{Anexo. El catálogo de lugares de turismo dark: algunos ejemplos reseñables en España y el Mundo}

Para tener una visión más holística del concepto dark y del nuevo orden clasificatorio con sus categorías y subcategorías, y con idea de conocer mejor la profundidad y la diversidad de los recursos dark en el mundo, resultaba de una imperiosa necesidad establecer una relación amplia de ejemplos y casos a nivel mundial con todas las categorías secundarias de esta modalidad turística.

Mediante la ejemplificación por categorías (A, B, C y D), se ha pretendido fundamentar la idea de que existen suficientes recursos dark en el Mundo y también en España para poder confeccionar rutas temáticas de carácter local, nacional o incluso internacional. A continuación en la Tabla 4 se muestra una relación de ejemplos que sustentan y justifican la desagregación en 20 categorías secundarias 
Tabla 4: Conjunto de ejemplos por categorías del nuevo espectro dark.

\begin{tabular}{ccc}
\hline Categoría & $\begin{array}{c}\text { Categorías / Categorías secundarias } \\
\text { y subcategorías secundarias }\end{array}$ & $\mathbf{N}^{\mathbf{0}}$. Ejemplos \\
\hline A & A.1 - A.8 & 45 \\
B & B. $9-$ B. 14 & 29 \\
C & C. $15-$ C.18 & 24 \\
D & & 13 \\
EJEMPLOS TOTALES & & $\mathbf{1 1 1}$ \\
\hline
\end{tabular}

Elaboración propia

Ejemplos de la categoría A [1-8]

A.1 Fábricas de entretenimiento - Parques temáticos y espectáculos de terror

1- The Bates Motel and Hauted Hayride (Pennsylvania, EE.UU.)

1- Pesadilla en Budapest (Budapest, Hungría)

1- Horrorland (Barcelona, España)

1- London Dugeon (Londres, Reino Unido)

A.2 Lugares de ficción - Sets de películas de terror/Enclaves de fama

2- El parque estatal Seneca Creek "El proyecto de la bruja de Blair" (EE.UU.)

2- El Motel Bates de Psicosis en Universal Studios (EE.UU.)

2- La casa de Sawyer y la gasolinera de "La matanza de Texas" en Kingsland y Bastrop (EE.UU.)

2- El cementerio de Pittsburgh "La noche de los muertos vivientes" (EE.UU.)

2- El Timberline Lodge en Mt Hood de la película "El resplandor” (EE.UU.)

2- La casa y set de rodaje de la película de terror Scream (EE.UU.)

\section{A.3 Eventos y congregaciones - Festividades de la muerte}

3- La danza de la muerte de Verges (España)

3- El día de los muertos (México)

3- El Pchum Ben “día de los ancestros" (Camboya)

3- Halloween (EE.UU.)

3- El festival de Obon (Japón)

3- El festival de los fantamas hambrientos "El festival Yulan" (China)

\section{A.4 Enclaves de conflicto - Escenarios bélicos}


4- El centro de Alepo (Siria)

4- El desembarco en la costa de Normandía (Francia)

4- Campo de batalla de la I Guerra Mundial (Ypes, Bélgica)

4- Pearl Harbour (EE.U.U.)

4- Los restos de la antigua Hiroshima y Nagasaki (Japón)

4- Refugios de la Guerra Civil Española (Almería, España)

A.5 Lugares de descanso - Panteones, cementerios, mausoleos...

5- El cementerio de Père-Lachaise (París, Francia)

5- El antiguo cementerio judío (R. Checa)

5- El cementerio de la Almudena (Madrid, España)

5- El cementerio de la Recoleta (Buenos Aires, Argentina)

5- El cementerio de Highgate (Londres, Reino Unido)

\section{A.6 Santuarios especiales - Veneración a ídolos fallecidos}

6- El palacio de Kensington (Londres, Reino Unido)

6- El mausoleo de Lenin (Moscú, Rusia)

A.7 Lugares de descanso subterráneos o de exposición - Catacumbas, osarios...

7- Las catacumbas de París (Francia)

7- Las catacumbas de San Calixto (Roma, Italia)

7- Las catacumbas de los Capuchinos (Palermo Italia)

7- Las catacumbas de Kom ash-Shuqqafa (Alejandría, Egipto)

7- Las catacumbas de Milos (Milos, Grecia)

7- Las catacumbas de San Pablo (Rabat, Malta)

7- El osario de Sedlec (Sedlec, República Checa)

7- El osario de Wamba (Valladolid, España)

7- La capilla de las calaveras (Czermna, Polonia)

7- La iglesia de las calaveras de San Francisco (Évora, Portugal)

7- Sala de los huesos de San Bernardino alle ossa (Milán, Italia)

7- Las Criptas de San Francisco (Lima, Perú)

7- Museo de las momias (Guanajuato, México)

\section{A.8 Exposiciones - Museos temáticos y exposiciones médicas explícitas}

8- El Museo Kunstkamera (San Petersburgo, Rusia) 
8- El Museo de anatomía Pedro Ara (Córdoba, Argentina)

8- El museo de la muerte (San Juan del Río, México)

\section{Ejemplos de la categoría B [9-14]}

\section{B.9 Recreaciones de secuestros, asesinatos y torturas}

9- Recreaciones de secuestros y torturas por encargo (México)

9- Recreaciones de secuestros a la carta, (Besançon, Francia)

B.10 Museos para morir / objetos fetiches de asesinatos / Museos de la muerte

10- Museo de la muerte (Los Ángeles, EE.UU.)

10- Museo de la muerte (Nueva Orleans, EE.UU.)

10- Museo de asesinos en serie (Florencia, Italia)

10- El museo del crimen (Londres, Reino Unido)

10- La mansión del terror de Mackney Manor (San Diego, Estados Unidos)

B.11 Accidentes, desastres y tragedias - Desastres nucleares y atentados terroristas

11- El desastre radioactivo Chernóbil (Ucrania)

11- El memorial del atentado del 11S (EE.UU.)

11- El Memorial del atentado del 11M (España)

B.12 Enclaves con fenómenos paranormales - Pueblos con fantasmas, casas y castillos

12- El pueblo de Belchite (Zaragoza, España)

12- El pueblo de Oradour-sur-Glane (Francia)

12- 112 de Ocean Avenue (Amityville, Nueva York, EE.UU.)

12- Loftus Hall (Wexford, Irlanda)

12- Hacienda The Myrtles (Louisiana, EE.UU.)

12- Mansión LaLaurie (Nueva Orleans, EE.UU.)

12- Mansión Rose Hall (Montego Bay, Jamaica)

12- El palacio de Linares (Madrid, España)

\section{B.13 Enclaves religiosos - Torturas / Interrogatorios}

13- Museo de la tortura de la santa inquisición (Toledo, España)

13- Museo de la tortura de la santa inquisición (Santillana del Mar, España)

13- Museo de la tortura medieval (Praga, Rep. Checa) 
13- Museo de la tortura (Ámsterdam, Holanda)

13- Museo medieval del crimen (Rothenburg ob der Tauber, Alemania)

13- Museo de la tortura (México D.F, México)

\section{B.14 Mazmorras - Mazmorras / Calabozos / Cárceles}

14- Las galerías de la justicia de Nottingham (Reino Unido)

14- La Casa de las mazmorras (Cartagena de Indias, Colombia)

14- Las mazmorras del castillo de Špilberk (Brno, República Checa)

14- La prisión de Mamertine (Roma, Italia)

14- Castillo de Chillingham (Northumberland, Reino Unido)

\section{Ejemplos de la categoría $C$ [15-18]}

\section{C.1 Guetos y suburbios - Dangerous ghetto tours / Slum tours}

15 - Las favelas de Río de Janeiro (Brasil)

15 - Las comunas Cité Soleil (Haití)

15 - Los barrios bajos de Dharavi (Mumbai, India)

15 - Las colonias de Tijuana (México)

\section{C.2 Manifestaciones y tradiciones - Rituales a la muerte extremos}

16 - Los rituales 'Ma'nene' "sacar a pasear a los muertos"

(Pueblo Toraja, isla de Célebes, Indonesia)

16 - Las cremaciones en Ganges (Varanasi, India)

16 - El entierro celestial (Tíbet, China)

16 - Exhumaciones de huesos "el giro de los huesos" (Madagascar)

16 - Ingerir las cenizas de los difuntos (pueblo indígena yanomami, Brasil)

16 - Untar a los descendientes con fluidos de los muertos

(pueblos aborígenes, Australia)

16- Desenterrar huesos de familiares y confeccionar un osario

(Pueblos de la Península de Yucatán, México)

16- Mutilaciones de dedos para mostrar el dolor de la muerte de un familiar (Papúa Nueva Guinea)

\section{C.3 Enclaves de crímenes - Ruta por asesinatos célebres}


17- Los asesinatos de Jack el Destripador (Londres, Reino Unido)

17- El asesino del zodiaco (San Francisco, EE.UU.)

17- El caníbal Jeffrey Dahmer (Wilwaukee, EE.UU.)

17- El asesino H.H. Holmes (Chicago, EE.UU.)

17- Los estrangulamientos de Beacon Hill (Boston, EE.UU.)

17- El asesino en serie Ted Bundy (Seattle, EE.UU.)

17- El asesino del torso "carnicero loco" (Cleveland, EE.UU.)

17- Los crímenes de Charles Manson (Beverly Hills, EE.UU.)

\section{C.4 Campos de concentración / Centros de genocidio}

18 - Campo de concentración de Auschwitz (Brzenzinka, Polonia)

18 - Kigali Memorial Center del genocidio ruandés (Kigali, Ruanda)

18 - Museo de los crímenes genocidas “Tuol Sleng” (Nom Pen, Camboya)

18 - Museo del genocidio armenio (Ereván, Armenia)

\section{Ejemplos de la categoría $D$ [19-20]}

\section{D1 Castigos públicos:}

19- Los latigazos o los azotes con cañas (Arabia Saudí, Irán, Sudán, Singapur, Brunei, Indonesia y Malasia)

19- La operación de cegar los ojos con ácido (Irán)

19- El proceso de amputar extremidades (Arabia Saudí, Irán y Sudán)

\section{D2 Ejecuciones públicas:}

20- Las ejecuciones públicas en forma de ahorcamientos, lapidaciones o decapitaciones (Arabia Saudí, Afganistán, Irán, Irak, Somalia, Pakistán, Corea del Norte, Nigeria, Yemen).

\section{Referencias}

Arellano, C. R.; Rivera, C. J. \& MOLERO, A. V. (2013). Conducta del consumidor. Estrategias y políticas aplicadas al marketing. Madrid: ESIC.

Ashworth, G. J. \& Isaac, R. K. (2015) Have we illuminated the dark? Shifting perspectives on 'dark' tourism. Tourism Recreation Research, 40(3), 316-325

Ashworth, G., \& Hartmann, R. (2005). Horror and human tragedy revisited: the management of sites of atrocities for tourism. New York: Cognizant Communication Corporation.

Ayala Pérez, T. (2015). Redes sociales e hiperconectividad en futuros profesores de la generación digital. Ciencia, 26 (51), 244-270. 
Biran, A.; Poria, Y. \& Oren, G. (2011). Sought Experience at Dark Heritage sites. Annals of Tourism Research, 38 (3), 820-841.

Brown, L. (2016). Tourism and pilgrimage: Paying homage to literary héroes. International Journal of Tourism Research, 18(2), 167-175.

Chang, T.-Y. (2014). Dark tourism: The effects of motivation and environmental attitudes on the benefits of experience. Revista Internacional de Sociología, 72(2), 69-86.

Cheal, F., \& Griffin, T. (2013). Pilgrims and patriots: Australian tourist experiences at Gallipoli. International Journal of Culture, Tourism and Hospitality Research, 7(3), 227-241.

Collins-Kreiner, N. (2016). Dark tourism as/is pilgrimage. Current Issues in Tourism, 19, 185 $-189$.

Corden, W.Y.; Neary, J.P. (1982). Booming Sector and De-Industrialisation in a Small Open Economy. The Economic Journal, 92 (368), 825 y ss.

Dann, G. M. S. (1998). The dark side of tourism. Etudes et Rapports Série L, Sociology/Psychology/Philosophy/Anthropology, 14. Aix en Provence: Centre International des Recherches et d'Etudes Touristiques.

Dann, G. M. (2000). Differentiating Destinations in the Language of Tourism: Harmless Hype or Promotional Irresponsibility?. Tourism Recreation Research, 25(2), 63-75.

De Oliveira, G. (2007). Modelos teóricos aplicados al turismo. Estudios y perspectivas en turismo, 16 (01), 96-110.

Ebrahim-Zadeh, C. (2003). El síndrome holandés: demasiada riqueza malgastada. Finanzas y Desarrollo, 40, 50-65.

García, R. y Acevedo, J. (2010). El territorio como factor del desarrollo. Revista Semestre Económico, 13(27), 39-62.

Guzmán Cuevas, J.J. y Fontela Montes, E. (2003). Círculos viciosos y virtuosos del desarrollo económico. Estudios de economía aplicada, 21 (2), 221-242.

Goossens, C. (2000). Tourism Information and Pleasure Motivation. Annals of Tourism Research, 27 (2), 301-321.

Guolo, V. (1995). Cómo promover un turismo compatible. Milano: COM/I Edizione.

Hughes, H. L. (2002). Culture and Tourism: A Framework for Further Analysis. Managing Leisure, 7, 164-175.

Hyde, K., \& Harman, S. (2011). Motives for a secular pilgrimage to the Gallipoli battlefields. Tourism Management, 32(6), 1343-1351.

Jafari, J. (1986). The tourist system. The Social and Cultural Impact of International Tourism. Paris: Centre National of the Recherche Scientifique.

Jamal, T., \& Lelo, L. (2011). Exploring the conceptual and analytical framing of dark tourism: From darkness to intentionality. In R. Sharpley \& P. R. Stone (Eds.), Tourist experience: Contemporary perspectives (pp. 29-42). Abingdon, Oxon: Routledge.

Jurdao, F. (1992). Los mitos del turismo. Turismo y Sociedad. Madrid: Endymion.

Kazalarska, S. I. (2002). Dark Tourism: Reducing Dissonance in the Interpretation of Atrocity at Selected Museums in Washington, D.C.. Master Thesis, Sofia (Bulgaria): University of National and World Economics. 
Korstanje, M. E., \& Ivanov, S. (2012). Tourism as a Form of New Psychological Resilience: The Inception of Dark Tourism. Cultur: Revista de Cultura e Turismo, 6(4), 56-140

Kotler, P., \& Armtsrong, G. (2008). Principles of Marketing. Upper Saddle River: Pearson Education

Lennon, J., \& Foley, M. (2000). Dark Tourism: The attraction of Death and Disasters. London: Thomson Learning.

Liviano, D. (2019). ¿Qué tienen en común Chernóbil, Alcàsser y Puerto Hurraco?. [artículo en línea] Hosteltur (13 de agosto) [Fecha de consulta 10 de marzo de 2020] $<$ https://www.hosteltur.com/130565_que-tienen-en-comun-chernobil-alcasser-y-puertohurraco.html>

Miles, W. F. S. (2002). Auschwitz: Museum interpretation and darker tourism. Annals of Tourism Research, 29, 1175-1178.

Minic Natalija (2012). Development of "dark" tourism in the contemporary society. Zbornik Radova: Geografski institut 'Jovan Cvijić', 62(3), 81-103.

Moufakkir, O. y Burns, S.P.M. (Ed.) (2012). Controversies in Tourism. Cambridge: Cabi Publishing

Norrild, J. (2007). Patrimonio del Horror: gestión turística de los sitios del horror y la tragedia humana. Reseña de Publicaciones Especializadas. Estudios y Perspectivas en Turismo, 16(1), $121-125$

O’ Shaughnessy, J. (1991). Marketing Competitivo: un enfoque estratégico. Madrid: Editorial Díaz de Santos.

Park, Sun-Woo, Chul-Ho Cho, y Suk Choi. (2017). Social Multimedia Network Service Quality, User Satisfaction, and Prosumer Activity. Multimedia Tools \& Applications, 76 (16), 17213.

Pearce, P.L. \& Morrison, A. \& Rutledge, J. (1998). Tourism: bridges across continents. Sidney: McGraw-Hill.

Pelton, R. (2003) The World's Most Dangerous Places. London: Harper Resource.

Pérez de las Heras, M. (2004). Manual del turismo sostenible: cómo conseguir un turismo social, económico y ambientalmente responsable. Madrid: Mundi-Prensa.

Porter, M. (2006). Strategy and Society, the link between competitive advantage and corporate social responsibility. Cambridge: Harvad Business.

Remenyik, B. (2014). A development possibilities of thanatoturism in Hungary. Budapest: University of Budapest.

Richards, G. (2001). Cultural Attractions and European Tourism. USA: CABI Publishing

Rivera Mateos, M. (2012). Turismo responsable y relaciones interculturales en el contexto de la globalización. En Interculturalidad: un enfoque interdisciplinar / coord. Rodríguez, L. y Roldán A.R.(pp. 181-205). Córdoba: Universidad de Córdoba

Rivera Mateos, M. (2013). El turismo experiencial como forma de turismo responsable e intercultural. En Relaciones interculturales en la diversidad/coord. Rodríguez, L. y Roldán, A. R. (pp. 199-217). Córdoba: Universidad de Córdoba.

Rivera Mateos, M. (2016). Rutas turístico-culturales responsables y desarrollo local: la experiencia piloto de la "Ruta de la Córdoba de las Américas" (España). En Planificación 
territorial, desarrollo sustentable y geodiversidad / coord. Jurado, J.M. y Otros (pp. 20012015). Huelva: Instituto de Desarrollo Regional, Diputación y Universidad de Huelva.

Seaton, A.V. (1996). Guided by the dark: From thanatopsis to thanatourism. International Journal of Heritage Studies, 2, 9-79.

Seaton, A.V. (2009). Thanatourism and its discontents: an appraisal of a decade's work with some future issues and directions. In Jamal, T. and Robinson, M. (eds). The SAGE Handbook of Tourism Studies (pp.521-542). London: Sage.

Seaton, A. V., \& Lennon, J. J. (2004). Thanatourism in the early 21st century: Moral panics, ulterior motives and alterior desires. In T. V. Singh (Ed.). New horizons in tourism: Strange experiences and stranger practices (pp. 63-82). Wallingford: Glasgow Caledonian University.

Sharpley, R., \& Stone, P. R. (2009). Representing the Macabre: Interpretation, kitschification and authenticity". In R. Sharpley \& P. R. Stone (Eds.), The darker side of travel: The theory and practice of dark tourism (pp. 109-128). Aspect of Tourism Series, Bristol: Channel View Publications.

Sharpley, R., \& Stone, P.R. (2009). The Darker Side of Travel: The Theory and Practice of Tourism dark. Aspects of Tourism Series. Bristol: Channel View Publications.

Smith, V. (1996). War and Its Tourist Attractions. In A. Pizam and Y. Mansfeld (Ed.). Tourism, Crime and International Security Issues (pp. 247-264). Brisbane: John Wiley and Sons Ltd.

Stock, M. (coord.) (2003). Le tourisme. Acteurs, lieux et enjeux. París: Belin.

Stone, P. R. (2005). Dark Tourism Consumption" - A Call for Research. e-Review of Tourism esearch, 3(5), 109-117.

Stone, P. R. (2006). A dark tourism spectrum: Towards a typology of death and macabre related tourist sites, attractions and exhibitions". TOURISM: An Interdisciplinary International Journal, 52(2), 145-160.

Stone, P. R. (2009). It's a bloody guide: Fun, fear and a lighter side of dark tourism at the Dungeon Visitor Attractions, UK. In R. Sharpley \& P. R. Stone (Eds.). The darker side of travel: The theory and practice of dark tourism (pp. 167-185). Bristol: Channel View Publications.

Ugalde Binda, N. (2013). Investigación cuantitativa e investigación cualitativa: buscando las ventajas de las diferentes metodologías de investigación”. Ciencias Económicas, 2, 179.

Vázquez, A. (1988). Desarrollo local. Una estrategia de creación de empleo. Madrid: Pirámide.

Violier, P. (2008). Tourisme et développement local. Paris: Belin.

Woodside, A. \& Martin, D. (2008). Tourism management: analysis, behavior and strategy. UK; Cambridge, Mass CABI Pub, Wallingford,

Yuill, S. M. (2003). Dark Tourism: Understanding Visitor Motivation at Sites of Death and Disaster. Master Thesis, Texas: A\&M University. 